\title{
Supramolecular interlocked biphenyl ligands for enantioselective Ti-catalyzed alkylation of aromatic aldehydes
}

Jan Felix Scholtes, ${ }^{\mathrm{a}, \mathrm{b}}$ Oliver Trapp*a,b

${ }^{a}$ Department of Chemistry, Ludwig - Maximilians - Universität München, Butenandtstr. 5 - 13, 81377 Munich, Germany.

${ }^{b}$ Max - Planck - Institute for Astronomy, Heidelberg, Germany 


\section{Table of Content}

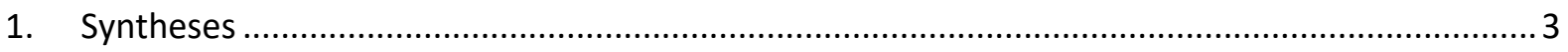

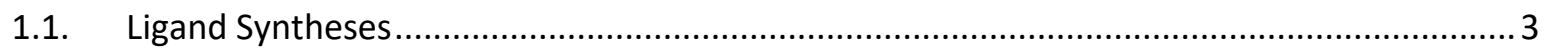

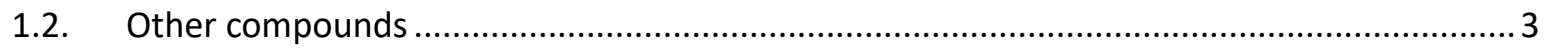

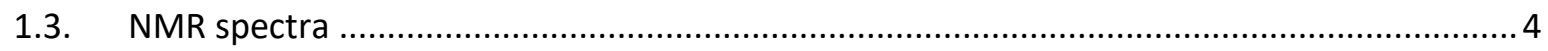

1.3.1. Compound 2

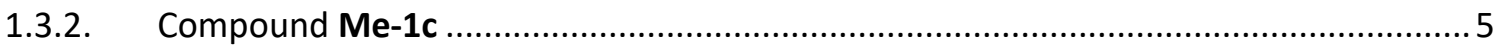

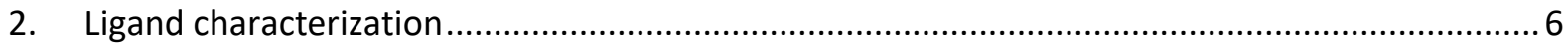

2.1. $C_{1}$-symmetric ligand appearance and amide proton shifts................................................. 6

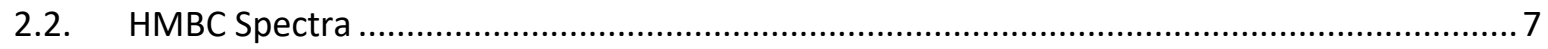

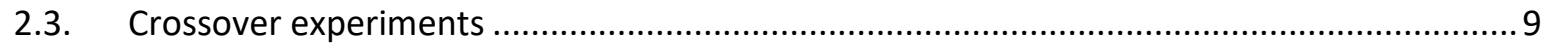

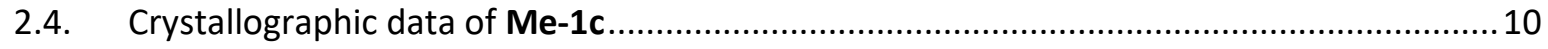

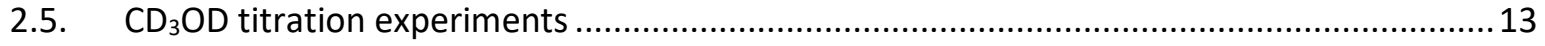

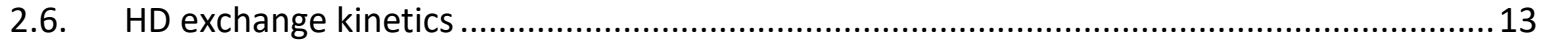

3. Enantioselective alkylation of aromatic aldehydes. …............................................................. 16

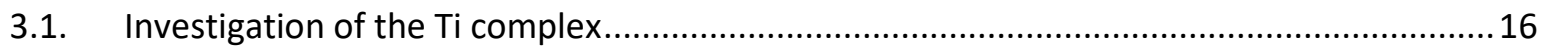

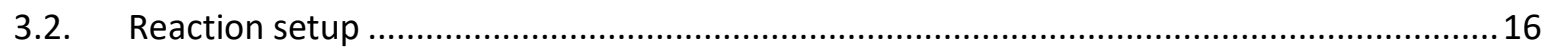

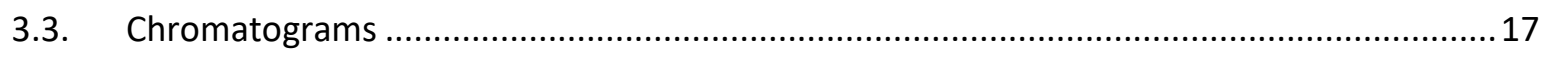

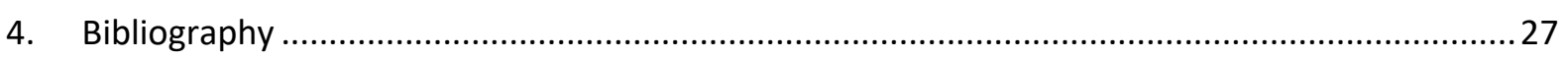




\section{Syntheses}

\subsection{Ligand Syntheses}
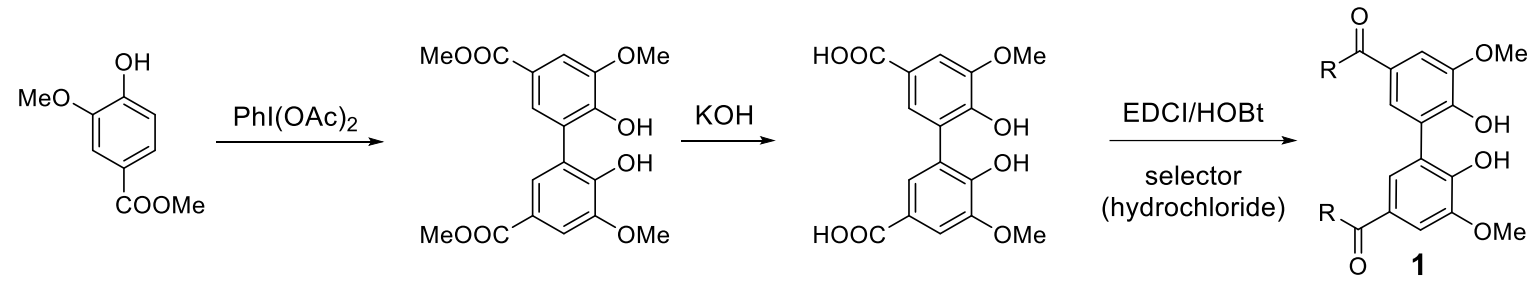

$\mathbf{R}=$
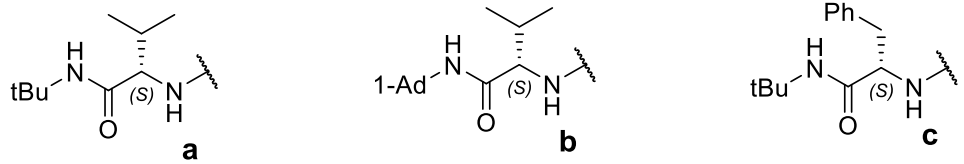

Figure S1: Synthetic overview for diols 1a-c.

The detailed synthetic procedure for BIPOL ligands has already been reported elsewhere. ${ }^{1}$

\subsection{Other compounds}

(S)-Ac-Phe-NHMe (3) is a known compounds and was prepared according to a published protocol. ${ }^{2}$ 


\subsection{NMR spectra}

\subsubsection{Compound 2}
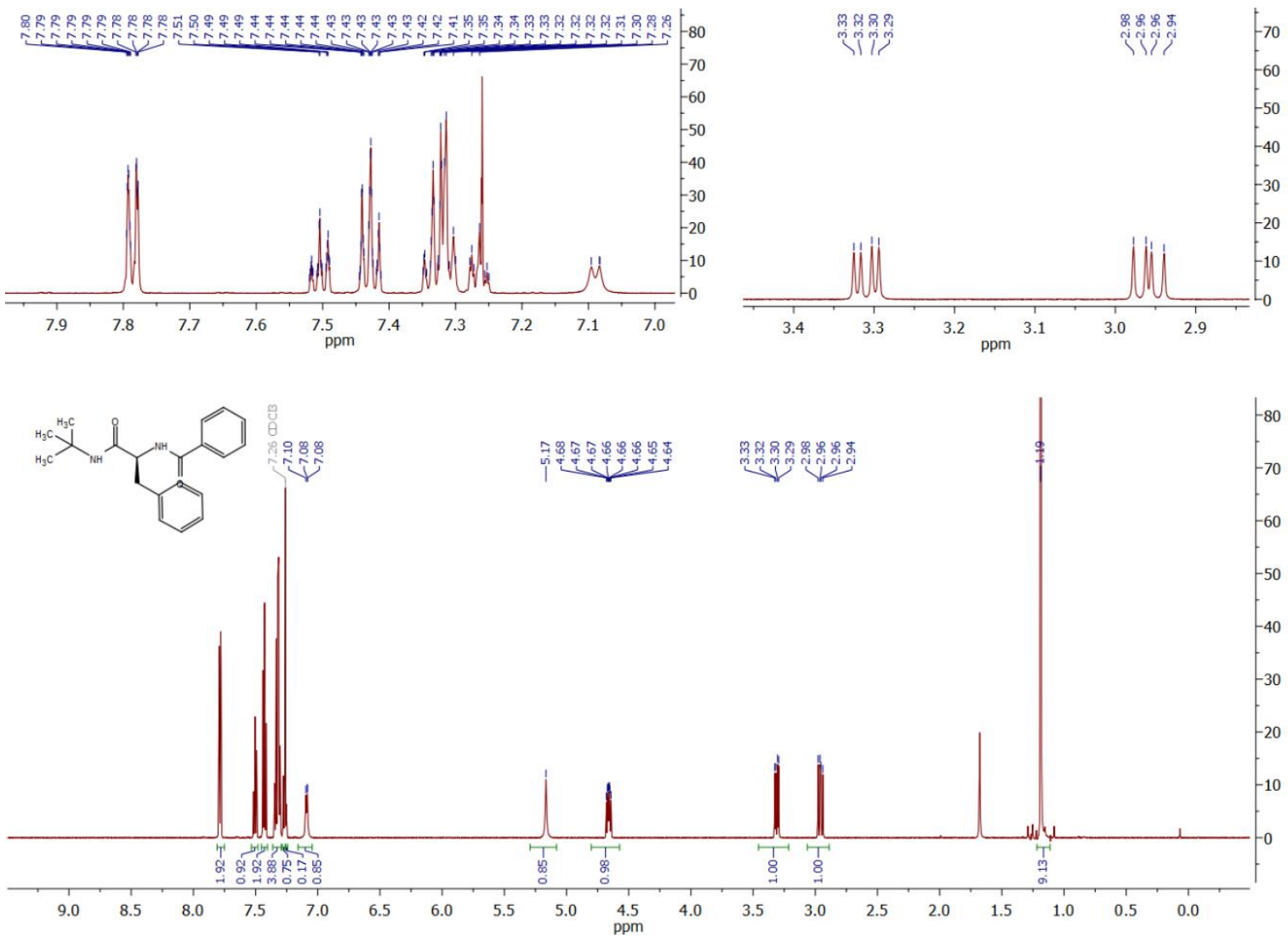

Figure S2: ${ }^{1} \mathrm{H}$ NMR spectrum of diamide 2. 


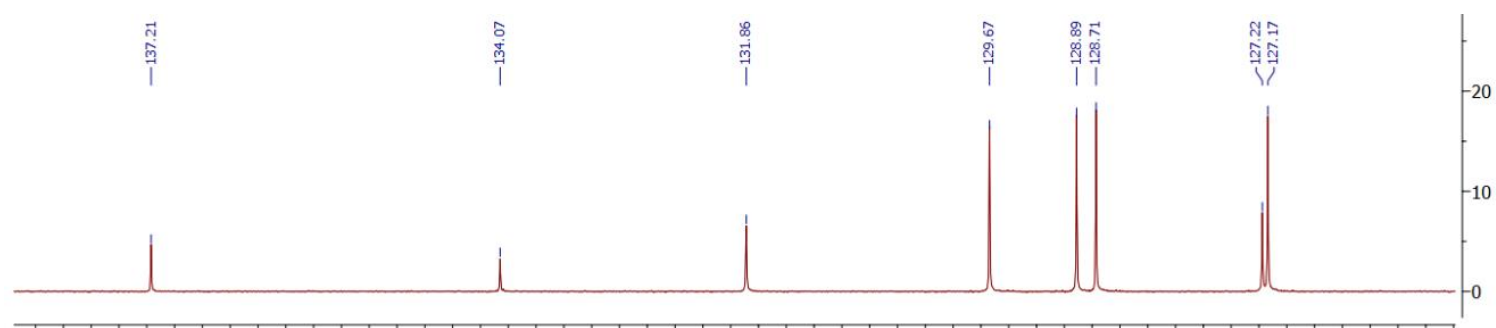

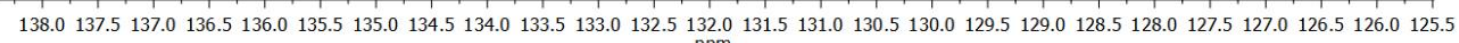
ppm

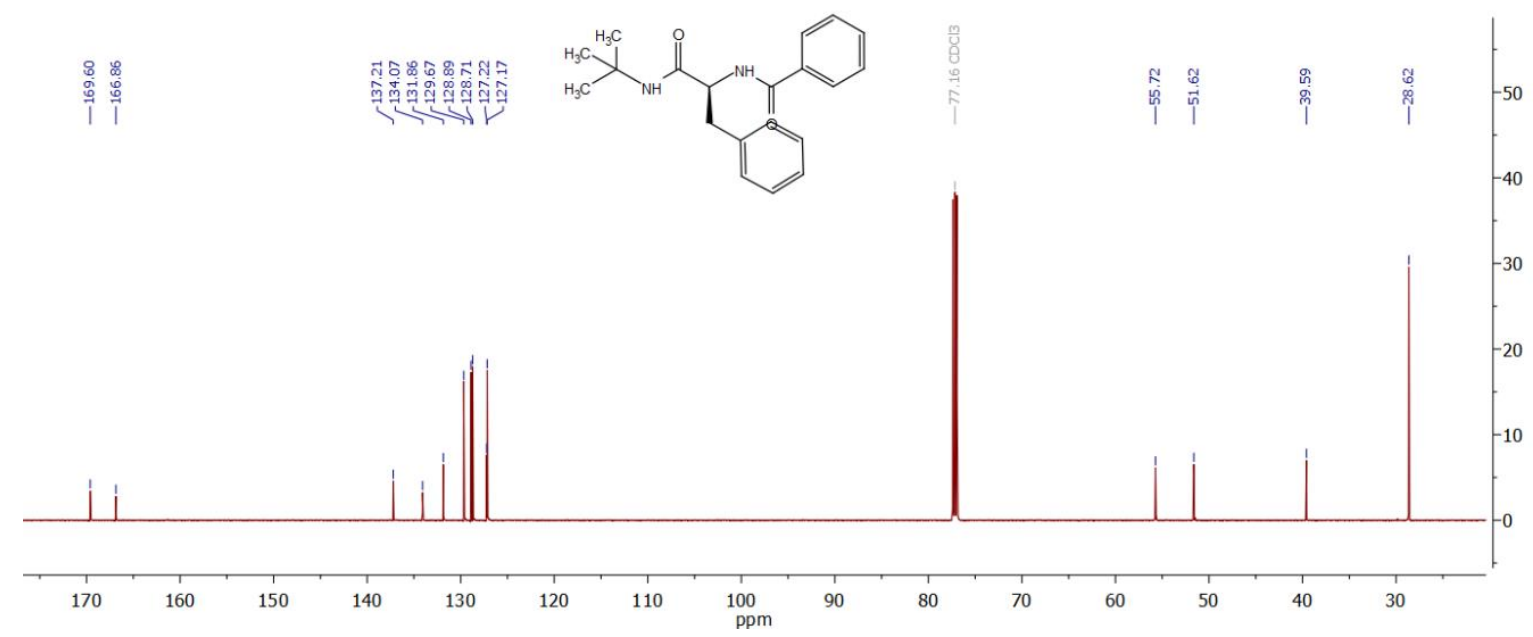

Figure S3: ${ }^{13} \mathrm{C}$ NMR spectrum of diamide 2.

\subsubsection{Compound Me-1c}
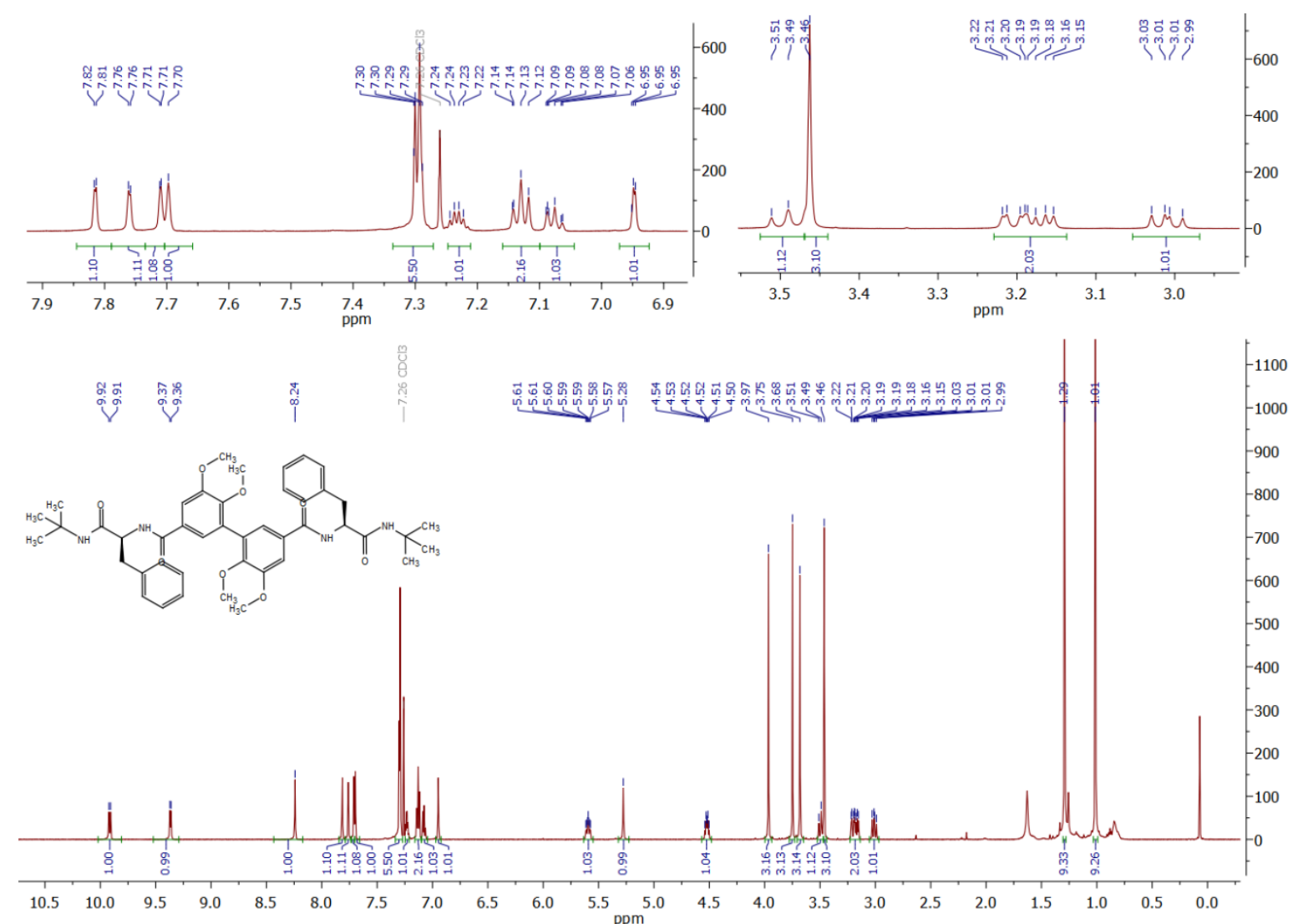

Figure S4: ${ }^{1} \mathrm{H}$ NMR spectrum of tetraamide Me-1c. 


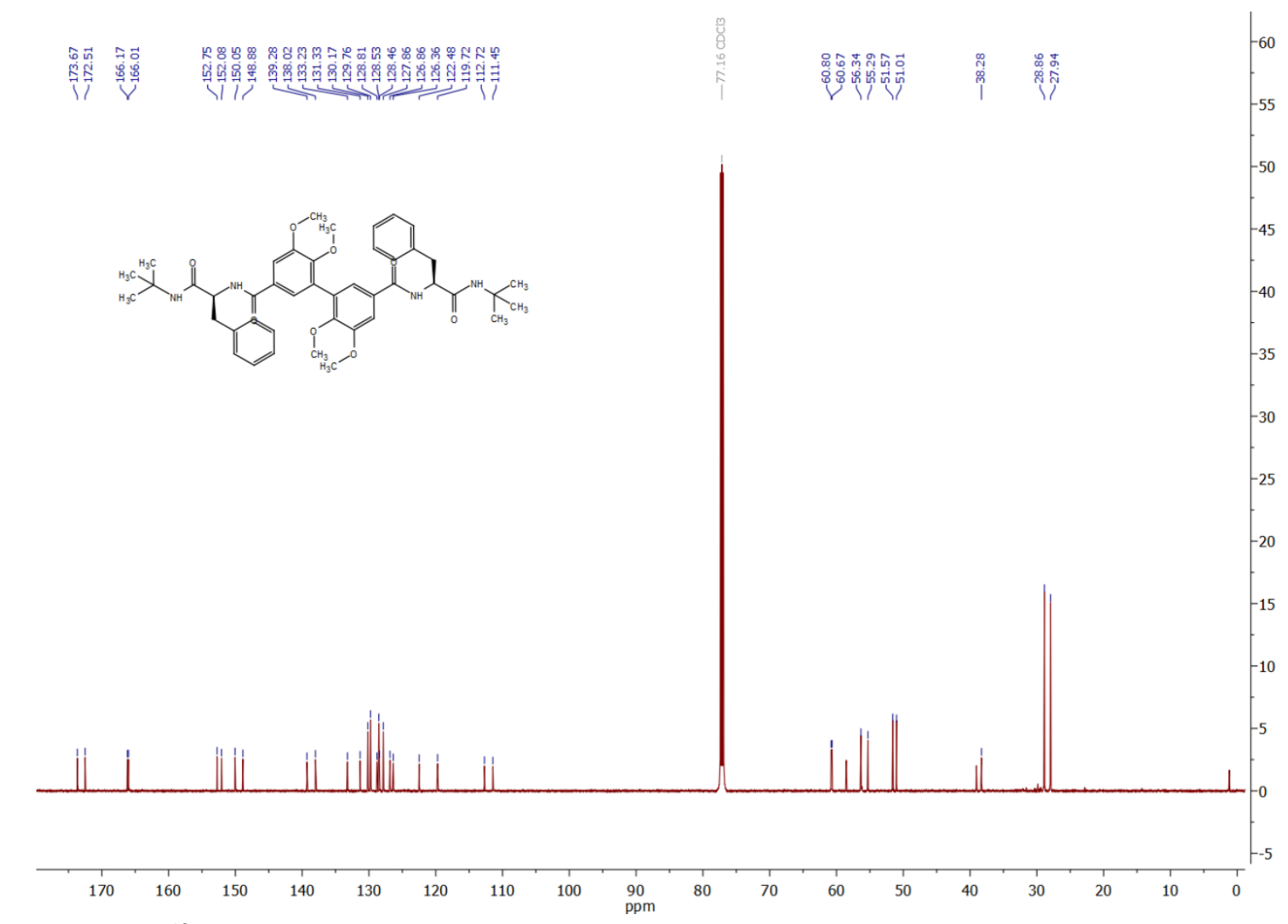

Figure S5: ${ }^{13} \mathrm{C}$ NMR spectrum of tetraamide Me-1c.

\section{Ligand characterization}

Additional information on the characterization of these ligand dimers can be found in ref. 1 of the SI.

\section{1. $C_{1}$-symmetric ligand appearance and amide proton shifts}

Ligand dimerization renders both halves of the biphenol ligand unsymmetrical. For each compound, an additional set of signals can be found in ${ }^{1} \mathrm{H}$ and ${ }^{13} \mathrm{C}\left\{{ }^{1} \mathrm{H}\right\}$ NMR spectra and the sets represent the inner sphere (green) and the outer sphere (orange) of the hydrogen bond complex. Signal set where linked by cross peaks in two-dimensional $\left\{{ }^{1} \mathrm{H}\right\}-\left\{{ }^{13} \mathrm{C}\right\}-\mathrm{HMBC}$ spectra (see below).

Strong hydrogen bonding (chelate effect and $\mathrm{H}$-bonding cooperativity) leads to a significant downfield shift for amide protons in ${ }^{1} \mathrm{H}$ NMR spectra. Respective signals for compounds $1 \mathrm{a}-\mathrm{c}$ are found between 5.34 (non-interacting amide proton $\mathrm{H}_{\mathrm{b}}{ }^{\prime}$, see structure below) and $10.10 \mathrm{ppm}$ (strongly bonded amide proton $\mathrm{H}_{\mathrm{a}}$ in the core of the dimer). 

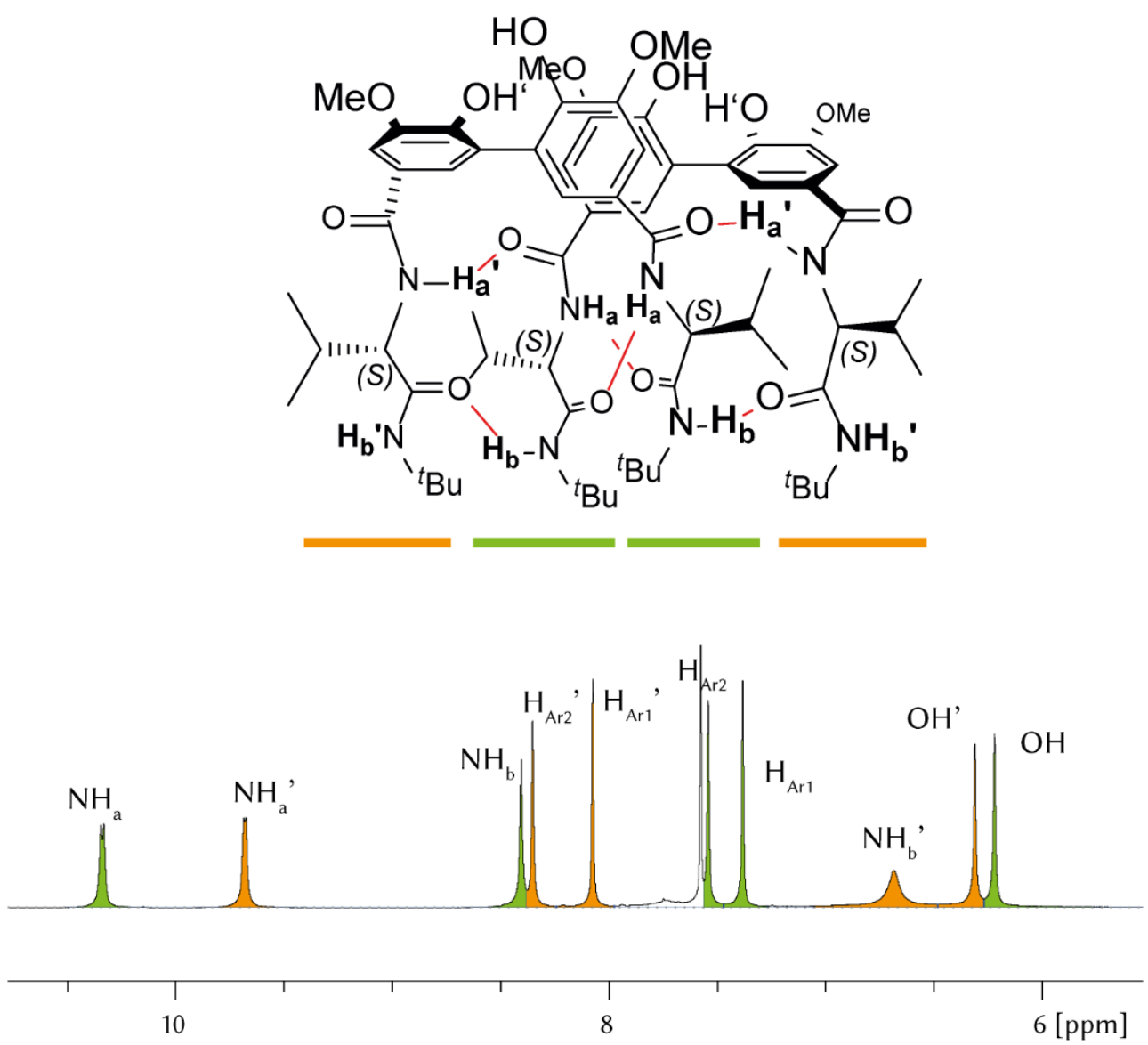

Figure S6: Aromatic section of the ${ }^{1} \mathrm{H}$ NMR spectrum of 1a where each molecule gives two signal sets of identical intensity representing the inner sphere (green, $X$ ) and the outer sphere (orange, $X^{\prime}$ ) of each subunit in the supramolecular dimer. Amide protons exhibit significant downfield shift due to strong hydrogen bonding.

\subsection{HMBC Spectra}

Two-dimensional HMBC NMR data of ligands 1a-c show cross peaks between protons belonging to the two different signal sets and quaternary carbons of the respective other set linking all signals in the spectrum to the same molecular scaffold. 


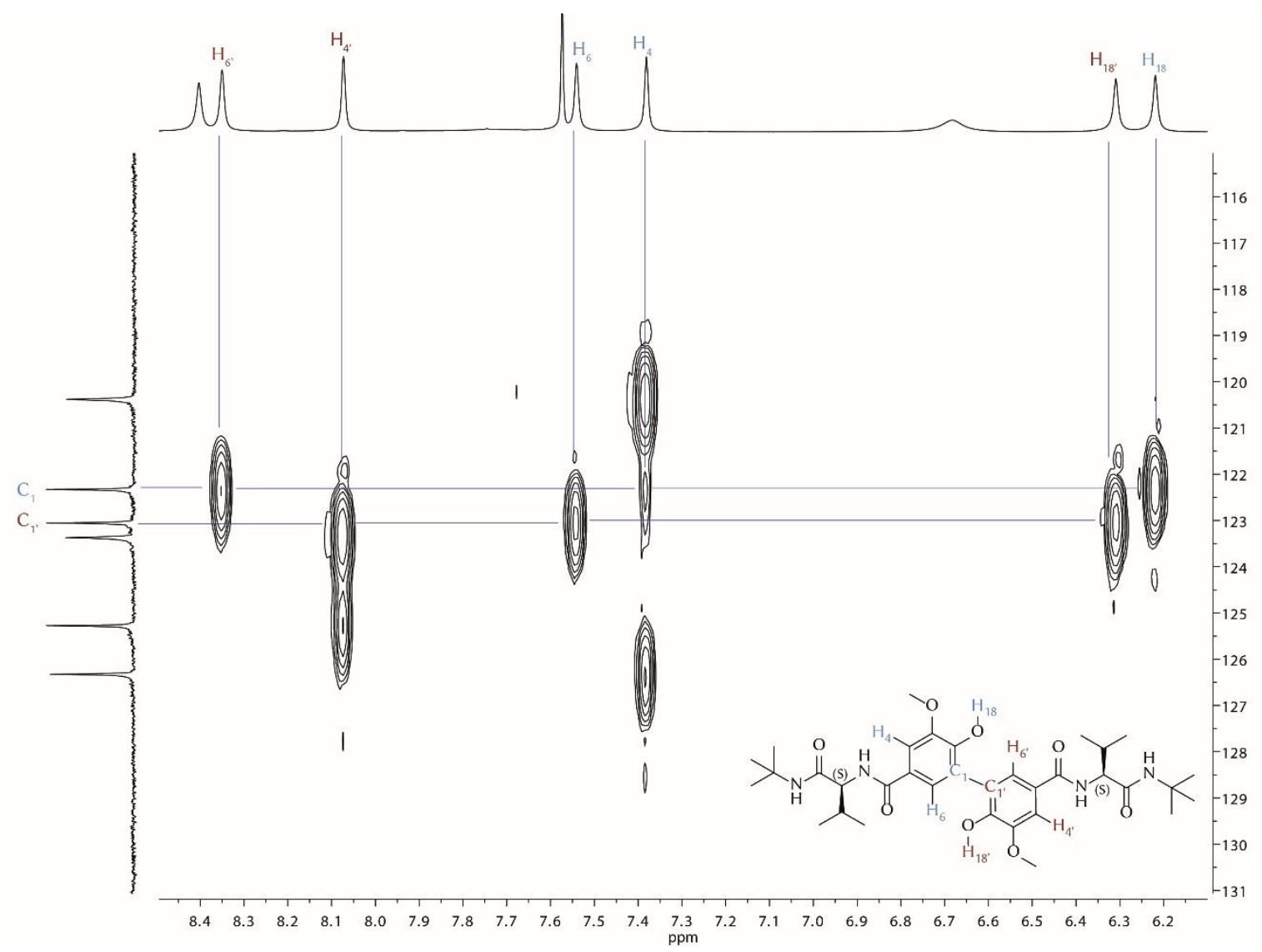

Figure S7: Section of HMBC spectrum of ligand precursor 1a with annotated cross peaks.

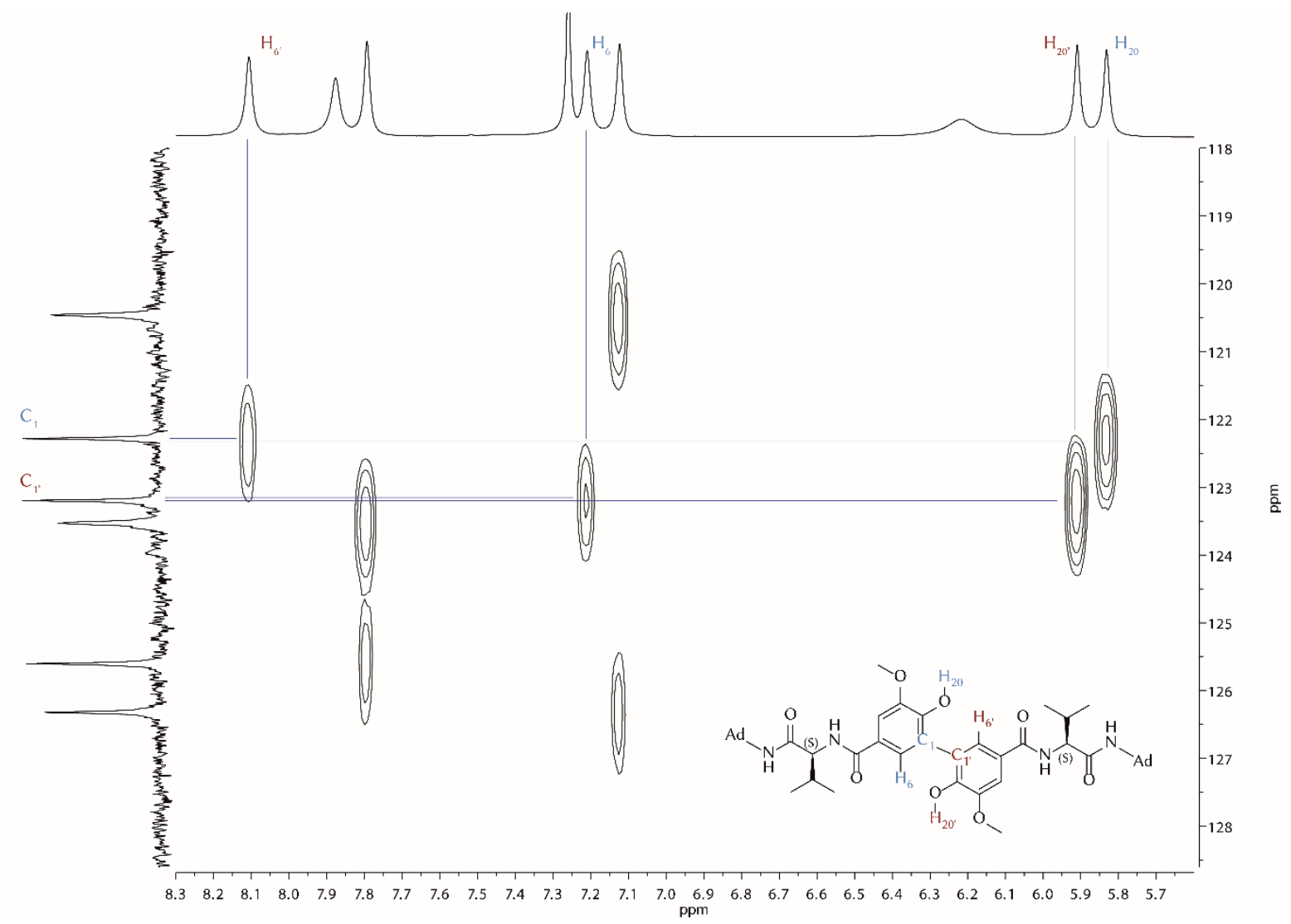

Figure S8: Section of HMBC spectrum of ligand precursor $\mathbf{1 b}$ with annotated cross peaks. 


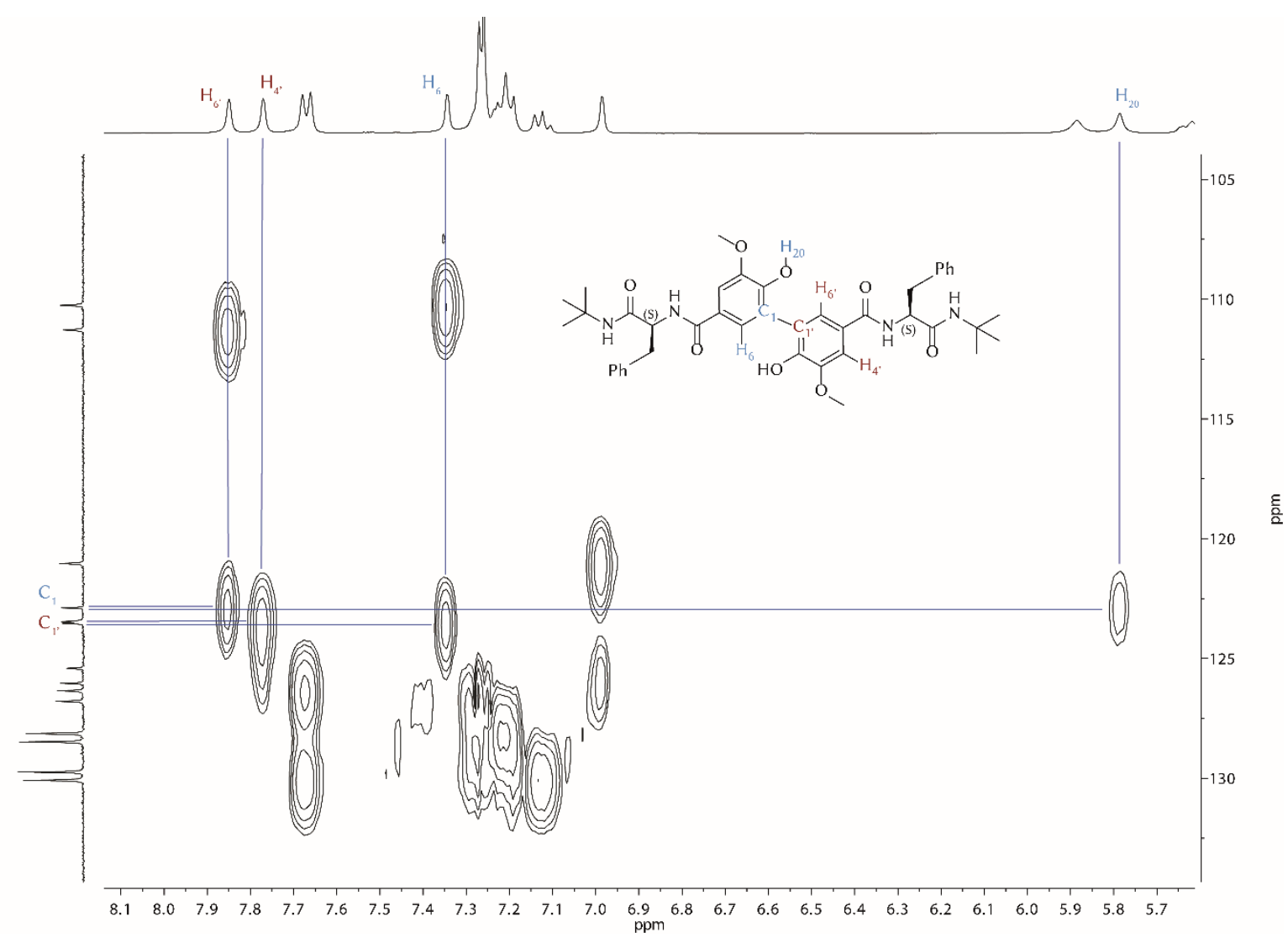

Figure S9: Section of HMBC spectrum of ligand precursor 1c with annotated cross peaks.

\subsection{Crossover experiments}

Diols $\mathbf{1 a}$ and $\mathbf{1 b}$ were mixed in dry $\mathrm{CDCl}_{3}$ to give a $5 \mathrm{mM}$ in each component. NMR spectra were collected at $-38{ }^{\circ} \mathrm{C}$ and compared to those of the isolated compounds under identical conditions. Mixing the ligands gives rise to a variety of new (partially overlapping) signals that can be attributed to the formation of the heterodimeric compound.

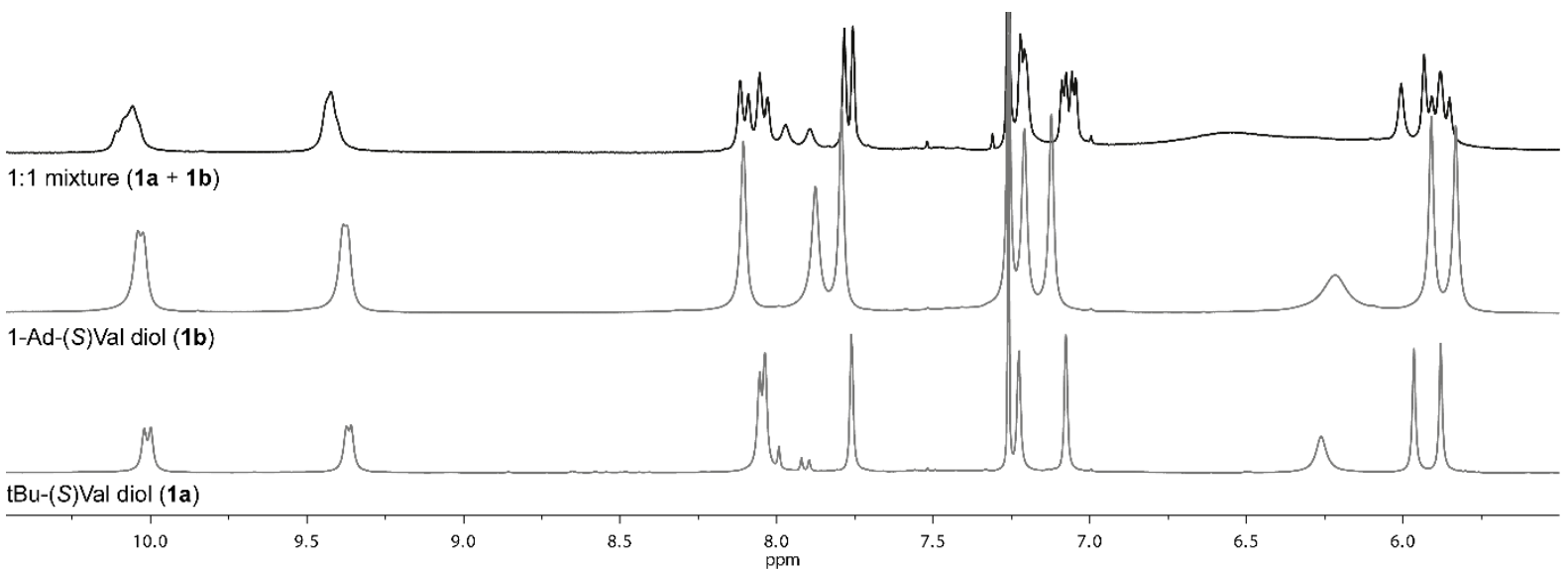

Figure S10: Section of ${ }^{1} \mathrm{H}$ NMR spectra of diols $\mathbf{1 a}, \mathbf{1} \mathbf{b}$ and their respective $1: 1$ mixture in $\mathrm{CDCl}_{3}$ 


\subsection{Crystallographic data of Me-1c}

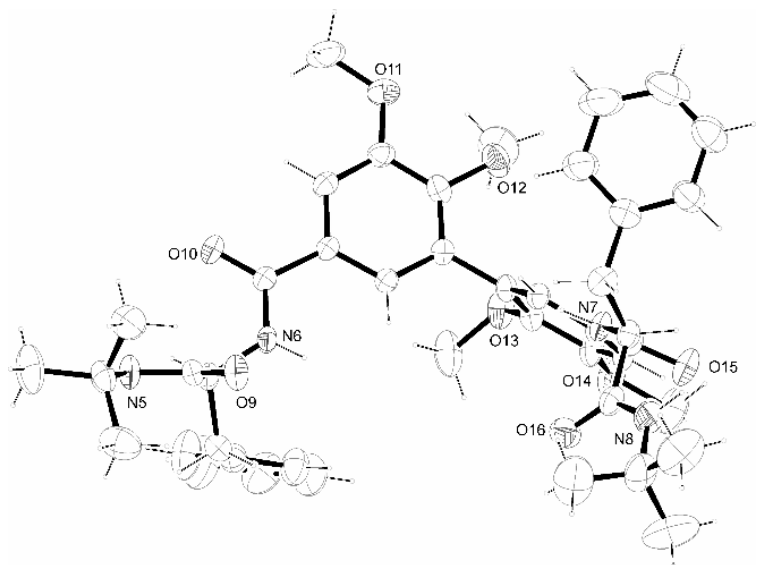

Figure S11: Crystal structure of Me-1c

\begin{tabular}{|c|c|c|c|}
\hline ID & wq035 & absorption correction & Multi-Scan \\
\hline net formula & $\mathrm{C}_{47.15} \mathrm{H}_{57.60} \mathrm{~N}_{4} \mathrm{O}_{8}$ & transmission factor range & $0.93-1.00$ \\
\hline$M_{\mathrm{r}} / \mathrm{g} \mathrm{mol}^{-1}$ & 808.37 & refls. measured & 41085 \\
\hline crystal size/mm & $0.100 \times 0.090 \times 0.040$ & $R_{\text {int }}$ & 0.0508 \\
\hline$T / K$ & 296.(2) & mean $\sigma(I) / I$ & 0.0648 \\
\hline radiation & MoKa & $\theta$ range & $2.332-25.350$ \\
\hline diffractometer & 'Bruker D8Quest' & observed refls. & 10885 \\
\hline crystal system & orthorhombic & $x, y$ (weighting scheme) & $0.0573,2.1296$ \\
\hline space group & 'P 212121 ' & hydrogen refinement & constr \\
\hline$a / \AA ̊$ & $17.3902(6)$ & Flack parameter & $-1.0(6)$ \\
\hline$b / \AA$ & $22.2927(10)$ & refls in refinement & 16733 \\
\hline$c / \AA ̊$ & $23.9010(11)$ & parameters & 1114 \\
\hline$\alpha /^{\circ}$ & 90 & restraints & 54 \\
\hline$\beta /^{\circ}$ & 90 & $R\left(F_{\text {obs }}\right)$ & 0.0612 \\
\hline$\gamma /{ }^{\circ}$ & 90 & $R_{\mathrm{w}}\left(F^{2}\right)$ & 0.1504 \\
\hline$V / \AA^{3}$ & $9265.8(7)$ & $S$ & 1.024 \\
\hline$Z$ & 8 & shift/error $\max$ & 0.001 \\
\hline calc. density/g $\mathrm{cm}^{-3}$ & 1.159 & max electron density/e $\AA^{-3}$ & 0.291 \\
\hline$\mu / \mathrm{mm}^{-1}$ & 0.079 & min electron density/e $\AA^{-3}$ & -0.296 \\
\hline
\end{tabular}




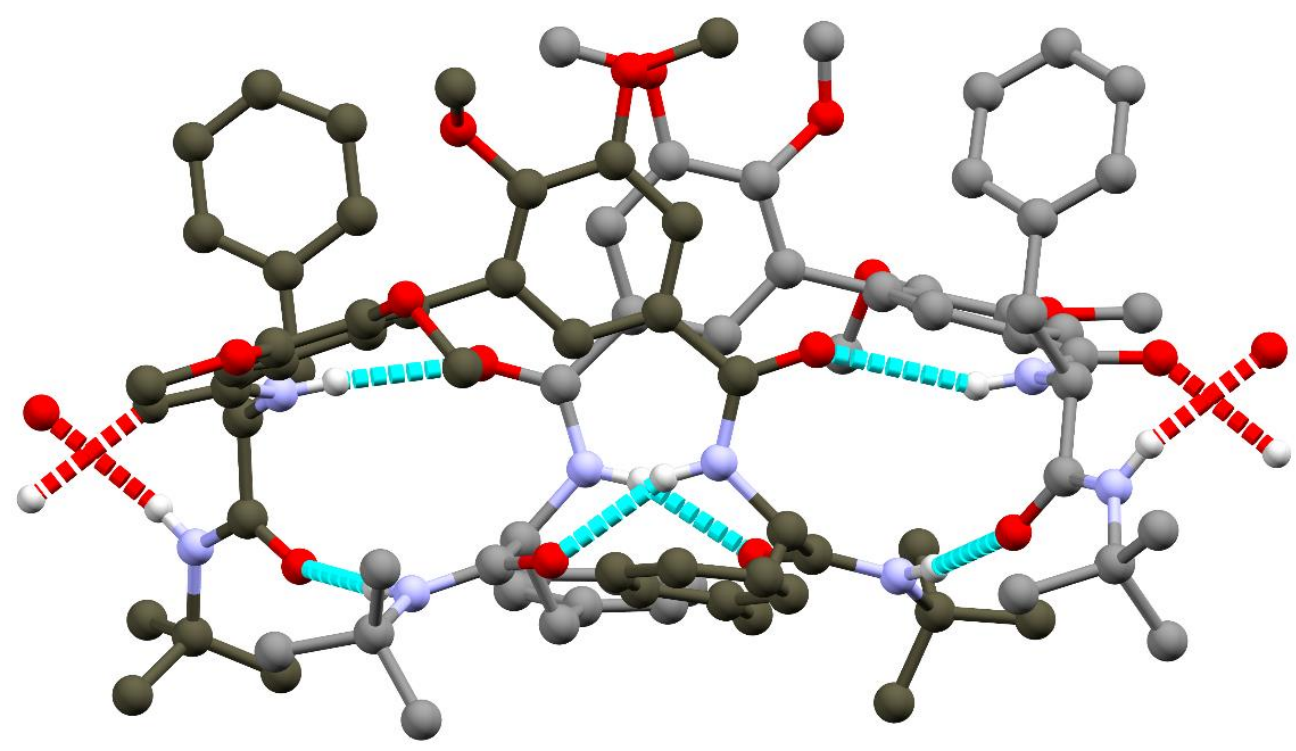

Figure S12: Front View. Representation of the single crystal X-ray structure of Me-1c. Two Rax molecules form a supramolecular $C_{2}$-symmetric dimer of $C_{1}$-symmetric subunits (carbon atoms of different subunits are indicated in black and grey). Hydrogen bonds are indicated with light blue lines (within the dimer) and red (to neighboring dimers structures). For improved clarity, non-relevant hydrogen atoms as well as solvent molecules are omitted and the disorder of one methoxy group is not shown. Nitrogen = blue, oxygen = red, hydrogen $=$ white.

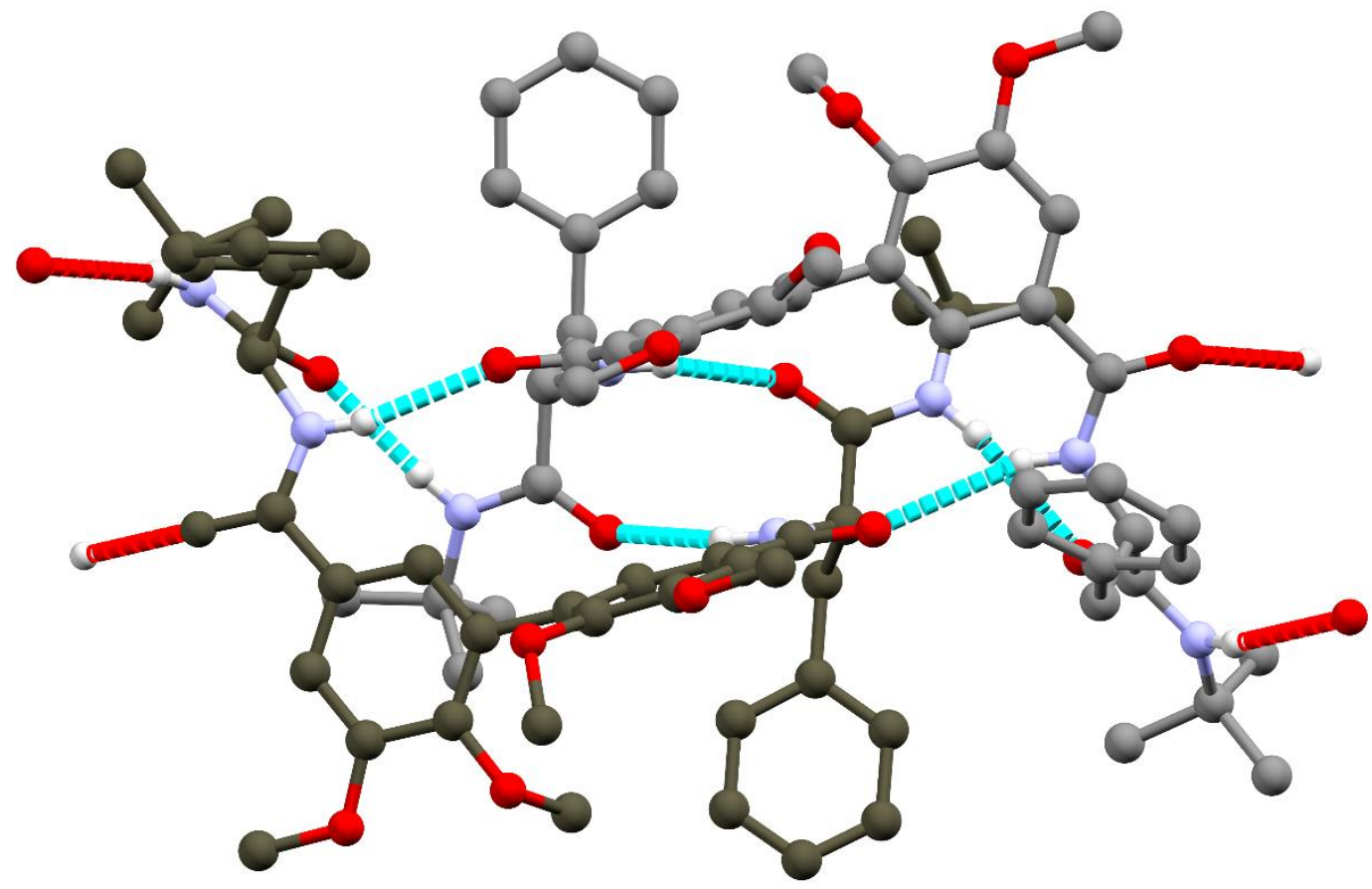

Figure S13: Top View. Representation of the single crystal X-ray structure of Me-1c. Two Rax molecules form a supramolecular $C_{2}$-symmetric dimer of $C_{1}$-symmetric subunits (carbon atoms of different subunits are indicated in black and grey). Hydrogen bonds are indicated with light blue lines (within the dimer) and red (to neighboring dimers structures). For improved clarity, non-relevant hydrogen atoms as well as solvent molecules are omitted and the disorder of one methoxy group is not shown. Nitrogen = blue, oxygen = red, hydrogen $=$ white. 


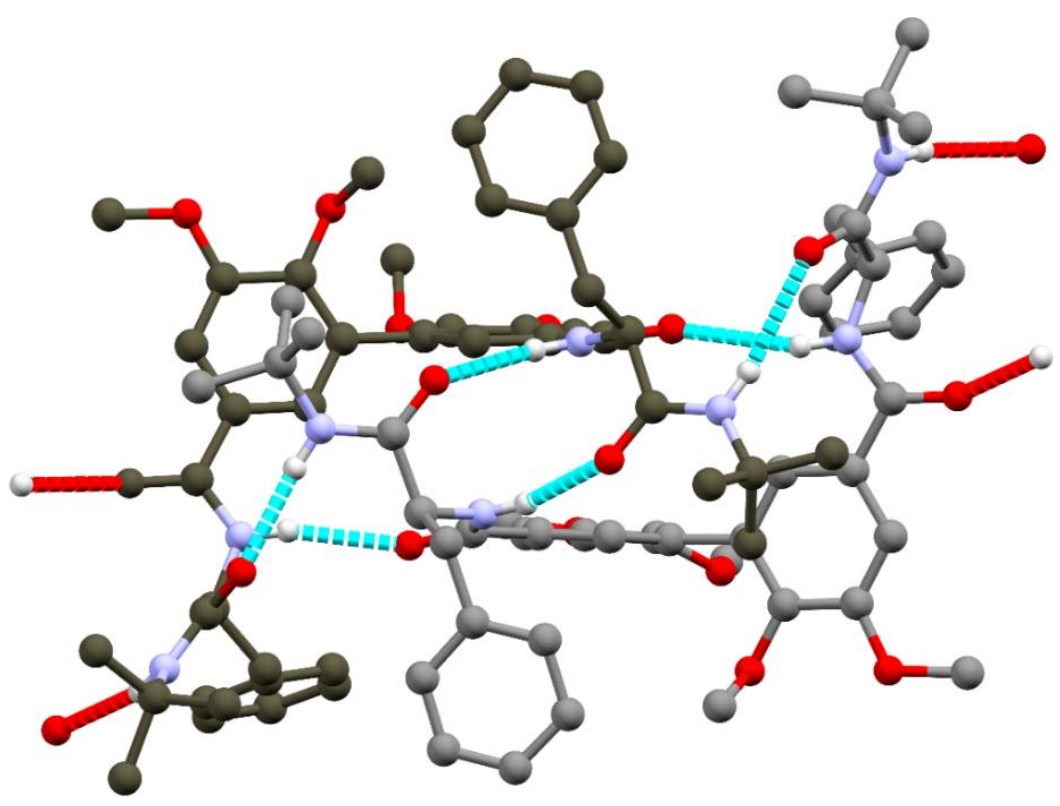

Figure S14: Bottom View. Representation of the single crystal X-ray structure of Me-1c. Two Rax molecules form a supramolecular $C_{2}$-symmetric dimer of $C_{1}$-symmetric subunits (carbon atoms of different subunits are indicated in black and grey). Hydrogen bonds are indicated with light blue lines (within the dimer) and red (to neighboring dimers structures). For improved clarity, non-relevant hydrogen atoms as well as solvent molecules are omitted and the disorder of one methoxy group is not shown. Nitrogen = blue, oxygen = red, hydrogen $=$ white

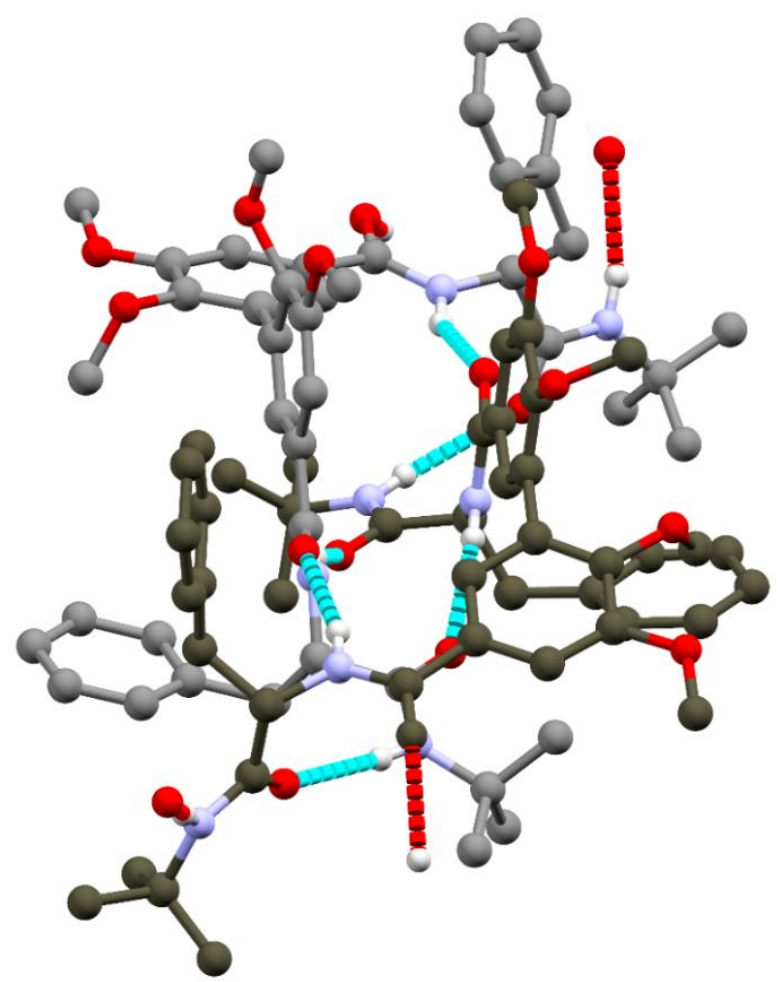

Figure S15: Side View. Representation of the single crystal X-ray structure of Me-1c. Two Rax molecules form a supramolecular $C_{2}$-symmetric dimer of $C_{1}$-symmetric subunits (carbon atoms of different subunits are indicated in black and grey). Hydrogen bonds are indicated with light blue lines (within the dimer) and red (to neighboring dimers structures). For improved clarity, non-relevant hydrogen atoms as well as solvent molecules are omitted and the disorder of one methoxy group is not shown. Nitrogen = blue, oxygen = red, hydrogen $=$ white. 


\section{5. $\mathrm{CD}_{3} \mathrm{OD}$ titration experiments}

Analyte solutions of compound $1 \mathrm{c}(20 \mathrm{mM})$ were prepared in solvent mixtures of $\mathrm{CDCl}_{3}$ and $\mathrm{CD}_{3} \mathrm{OD}$ with ratios 99:1, 90:10, 50:50 and 0:100. Both methanol and chloroform was taken from a freshly opened bottle and the latter was passed twice through a plug of dry, basic alumina to remove traces of acid. Spectra were calibrated to the terminal ${ }^{t} \mathrm{Bu}$ group at $0.94 \mathrm{ppm}$, which showed a negligible shift difference in all four spectra.
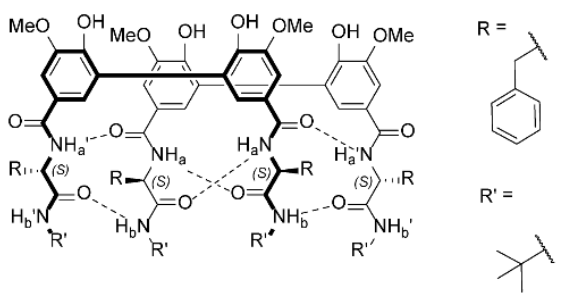

$$
\mathrm{CDCl}_{3}: \mathrm{CD}_{3} \mathrm{OD}
$$
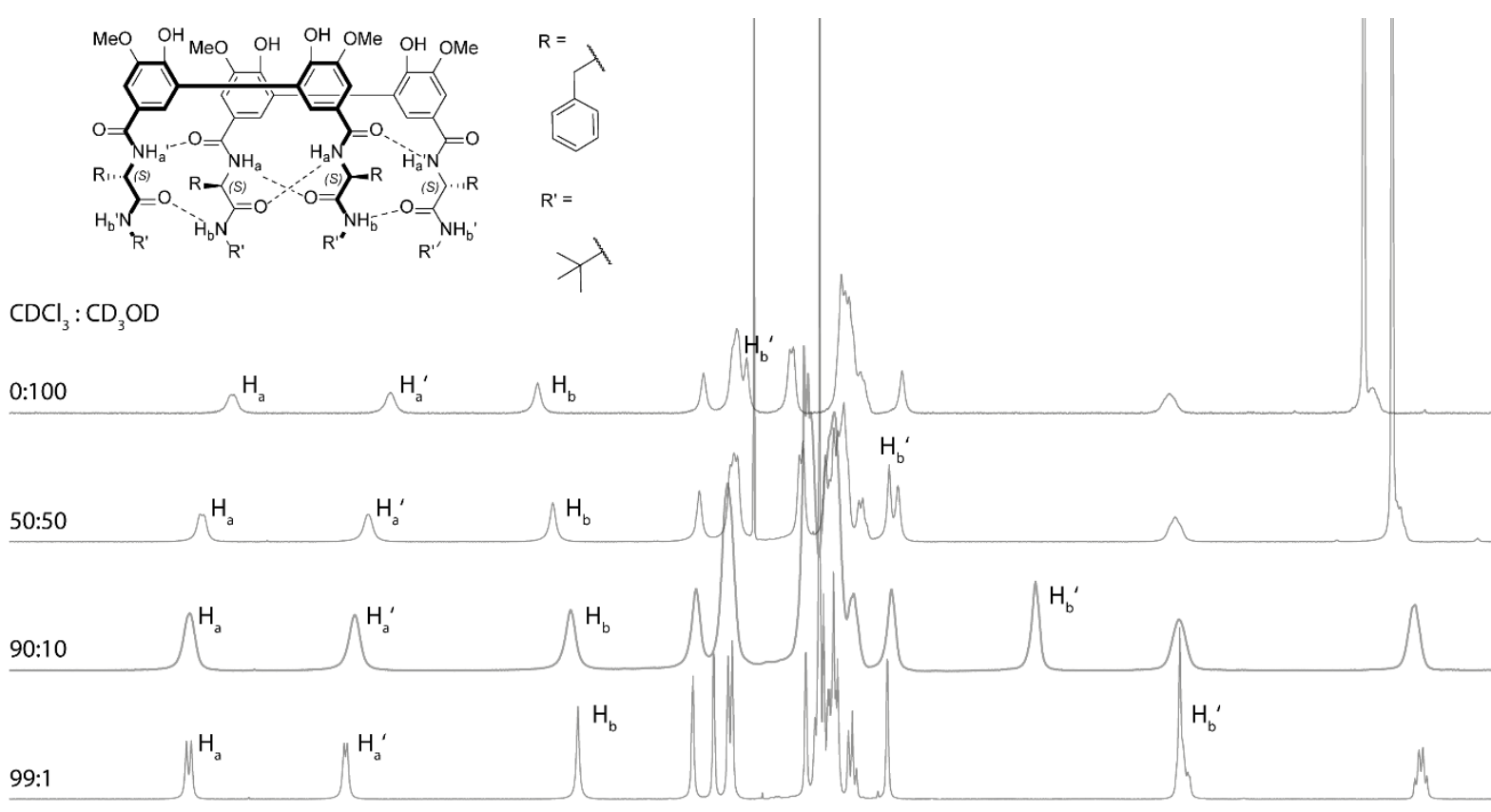

$\begin{array}{lllllllllllllllllllllllllllllllllllllllllllllll}10.8 & 10.6 & 10.4 & 10.2 & 10.0 & 9.8 & 9.6 & 9.4 & 9.2 & 9.0 & 8.8 & 8.6 & 8.4 & 8.2 & 8.0 & 7.8 & 7.6 & 7.4 & 7.2 & 7.0 & 6.8 & 6.6 & 6.4 & 6.2 & 6.0 & 5.8 & 5.6 & 5.4 & 5.2 & 5.0 & 4.8 & 4.6 & 4.4 & 4.2\end{array}$

Figure S16: Diol 1c in different mixtures of deuterated chloroform and methanol.

\subsection{HD exchange kinetics}

Analyte solutions of $1 \mathrm{c}$ and $\mathbf{2}$ with a concentration of $20 \mathrm{mM}$ and $40 \mathrm{mM}$, respectively, in freshly opened methanol-d4 were prepared. With a final methanol concentration of $24.6 \mathrm{M}, \mathrm{HD}$ exchange was considered to proceed with pseudo-first-order kinetics. Spectra were collected periodically with intervals suitable for the speed of exchange. All acquired spectra were baseline and phase corrected. The decay of the signal was evaluated relatively to the non-exchanging methin proton in the chiral center, H9. Regression curves were generated using Origin 16's quick fit functionality with the exponential decay function:

$$
y=y 0+A 1 * \exp (-(x-x 0) / t 1)
$$

The $y$-intercept is taken to normalize the final data to start from $100 \%$.

For proton $\mathrm{H}_{\mathrm{a}}{ }^{2}$, full signal decay was observed within $30 \mathrm{sec}$ when the first spectrum was measured. Half-life is thus estimated based on a signal decay to $1 \%$ within $30 \mathrm{sec}$ (equal to 6.65 half-lives): $\mathrm{t}_{1 / 2}\left(\mathrm{H}_{\mathrm{a}}{ }^{2}\right)$ $=4.5 \mathrm{sec}$.

Half-lives were read out and kinetic constants calculated according to first-order-kinetics: 


$$
t_{0.5}=\ln (2) / k_{e x}
$$
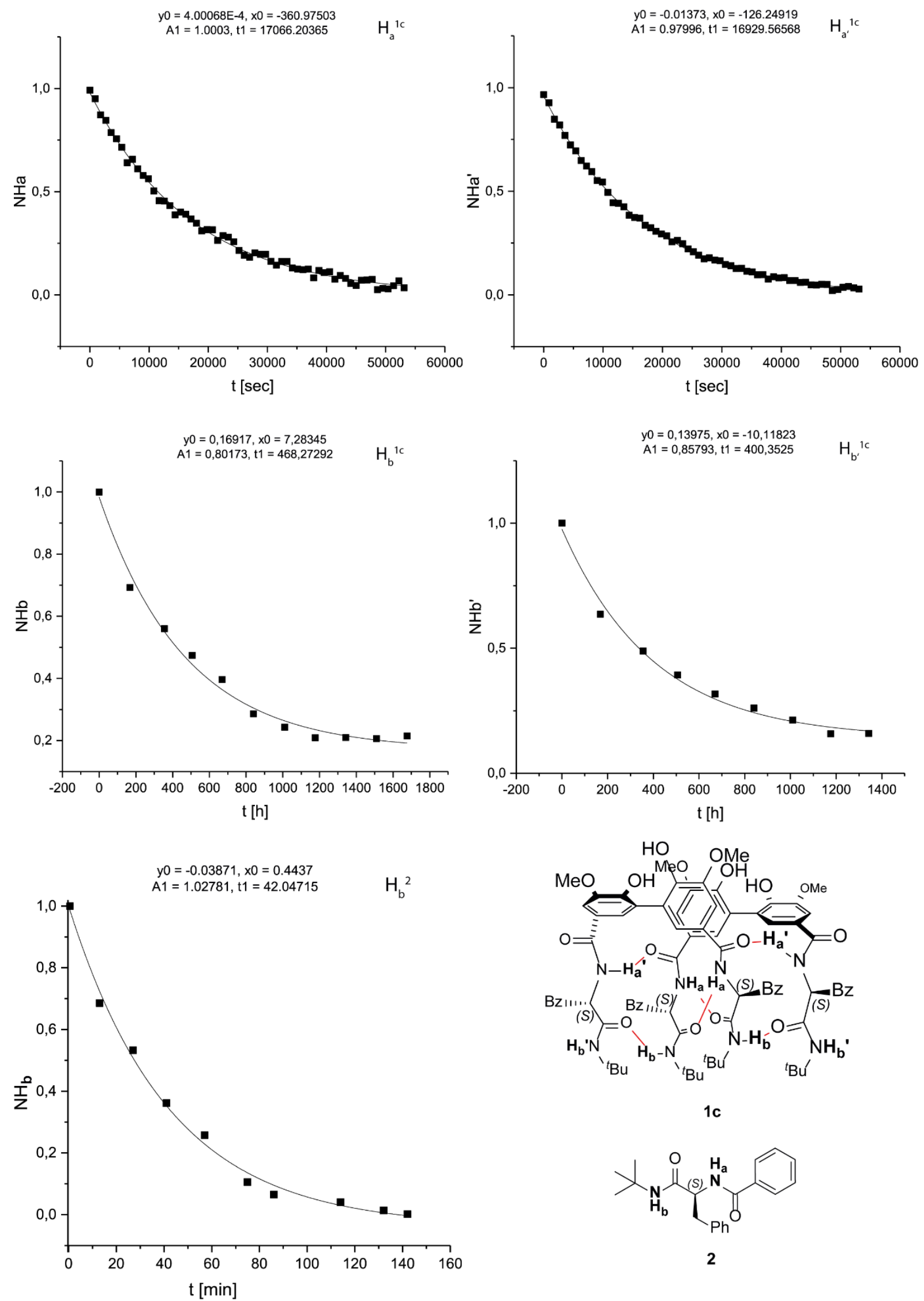

1c

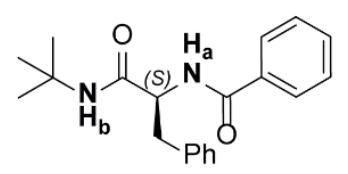

2

Figure S17: Deuterium exchange for amide protons of compounds $\mathbf{1 c}$ and $\mathbf{2}$. 
Slowdown factors describe deceleration of amide proton exchange compared to the model compound.

Table S1: Estimated half-life and exchange rates for HD exchange in methanol

\begin{tabular}{|c|c|c|c|c|c|c|}
\hline & $\begin{array}{l}\text { Diol 1c } \\
\mathrm{H}_{\mathrm{a}}\end{array}$ & $\mathrm{H}_{b}$ & $\mathrm{Ha}^{\prime}$ & $\mathrm{Hb}^{\prime}$ & $\begin{array}{l}\text { Diamide } 2 \\
\mathrm{H}_{\mathrm{a}}\end{array}$ & $\mathrm{H}_{b}$ \\
\hline $\begin{array}{c}t_{1 / 2} \\
{\left[10^{2} \mathrm{~min}\right]}\end{array}$ & 1.91 & 253.3 & 1.80 & 201.6 & $0.0008^{a)}$ & 0.28 \\
\hline $\begin{array}{c}k_{\mathrm{ex}} \\
{\left[\mathrm{sec}^{-1}\right]}\end{array}$ & $6.03 \cdot 10^{-5}$ & $4.56 \cdot 10^{-7}$ & $6.41 \cdot 10^{-5}$ & $5.72 \cdot 10^{-7}$ & $1.54 \cdot 10^{-1}$ & $4.18 \cdot 10^{-4}$ \\
\hline Slowdown factor ${ }^{\text {b) }}$ & $\begin{array}{c}2554 \\
-\end{array}$ & $\begin{array}{c}- \\
917\end{array}$ & $\begin{array}{c}2402 \\
-\end{array}$ & $\begin{array}{c}- \\
731\end{array}$ & $\begin{array}{l}1 \\
-\end{array}$ & $\begin{array}{l}- \\
1\end{array}$ \\
\hline
\end{tabular}

a) Complete exchange was observed before after 30 second. Half-life time was estimated based on multiple half-life times. b) Slowdown factor $=\mathrm{k}_{\text {ex }}\left(\mathrm{H}_{x}{ }^{2}\right) / \mathrm{k}_{\text {ex }}\left(\mathrm{H}_{x}{ }^{1 \mathrm{c}}\right)$ 


\section{Enantioselective alkylation of aromatic aldehydes.}

\subsection{Investigation of the Ti complex}

BIPOL 1c (10 mg, $13.5 \mu \mathrm{mol}, 1.00$ eq.) was dissolved in $0.5 \mathrm{ml}$ dry and degassed DCM-d2 ( ${ }^{1} \mathrm{H}$ NMR spectrum 1). Addition of $\left.\mathrm{Ti}^{(} \mathrm{O}^{\prime} \mathrm{Pr}\right)_{4}(4.1 \mu \mathrm{l}, 13.5 \mu \mathrm{mol}, 1.00$ eq.) gave a yellow precipitate (spectrum 2$)$. When another charge of $\mathrm{Ti}^{\prime}\left(\mathrm{O}^{\prime} \mathrm{Pr}\right)_{4}(24.6 \mu \mathrm{l}, 81.0 \mu \mathrm{mol}, 6.00$ eq. $)$ was added, solids re-dissolved and a clear, yellow solution formed (spectrum 3) Finally, Zn(Et) 2 (135 $\mu \mathrm{l}, 1 \mathrm{M}$ in hexane, $135 \mu \mathrm{mol}, 10.0$ eq.) was added (spectrum 4).

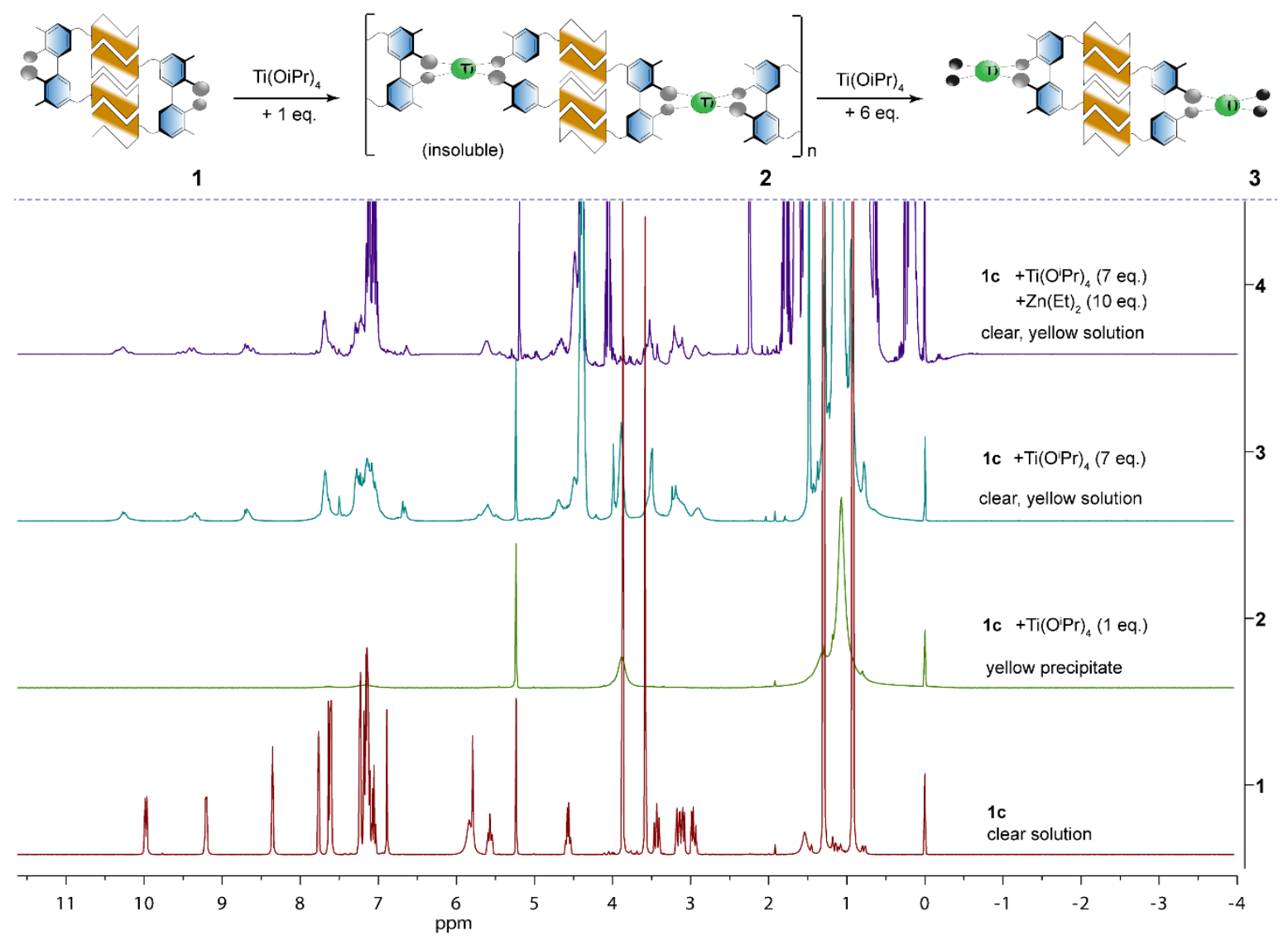

Figure S18: Investigation of the interplay of BIPOL ligand 1c, titanium precursor Ti( $\left.\mathrm{O}^{i} \mathrm{Pr}\right)_{4}$ and $\mathrm{Zn}(\mathrm{Et})_{2}$. Structures on top are suggestions. To improve clarity, a different representation is chosen for ligand dimer $\mathbf{1 c}$, where interlocked selectors are depicted in orange and white polygons, $R_{a x}$ rotamers in blue and titanium atoms in green.

\subsection{Reaction setup}

In a typical procedure, a heat-gun dried Schlenk flask equipped with a magnetic stirring bar was charged with ligand $(25 \mu \mathrm{mol})$ and titanium tetraisopropoxide $(175 \mu \mathrm{mol})$. Dry and degassed solvent $(1 \mathrm{ml}$, unless indicated otherwise) was added and the mixture was stirred for $10 \mathrm{~min}$, unless indicated otherwise. Diethyl zinc ( $375 \mu \mathrm{mol}$ from a $1 \mathrm{M}$ solution in toluene) was added and stirring was continued for another $10 \mathrm{~min}$. The temperature of the mixture was subsequently adjusted, the substrate (125 
$\mu \mathrm{mol})$ was added and stirring was continued for 16 hours. The reaction was stopped by addition of saturated ammonium chloride solution $(3 \mathrm{ml})$ and the product was extracted with ethyl acetate $(2 \times 3$ $\mathrm{ml}$ ). Combined organic layers were dried over sodium sulfate and conversion and enantioselectivity were determined by chiral GC (Chirasil- $\beta$-Dex) or HPLC (Chiracel OD-H). Retention times and absolute configuration were assigned by comparison with GC traces in literature, of known compounds or by identification with GC-MS.

\subsection{Chromatograms}

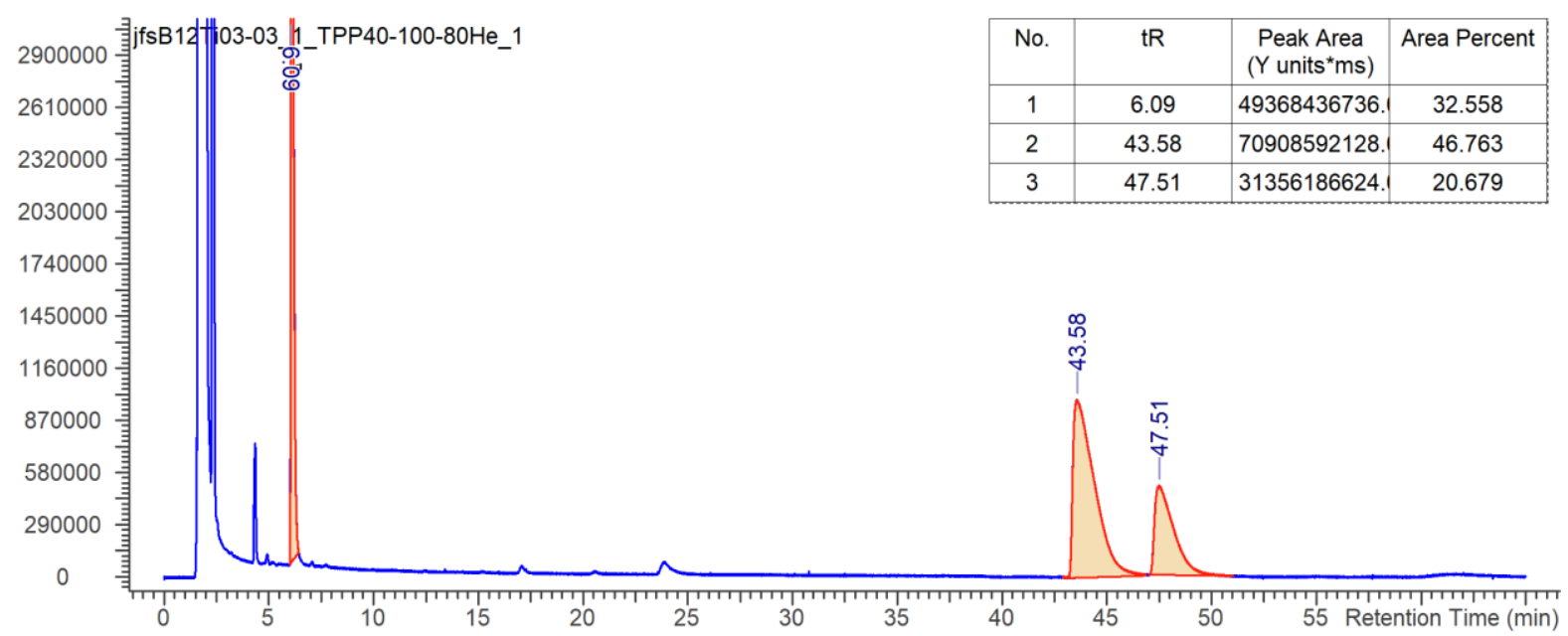

Figure S19: Experiment using ligand 1a (Table 2, Entry 1).

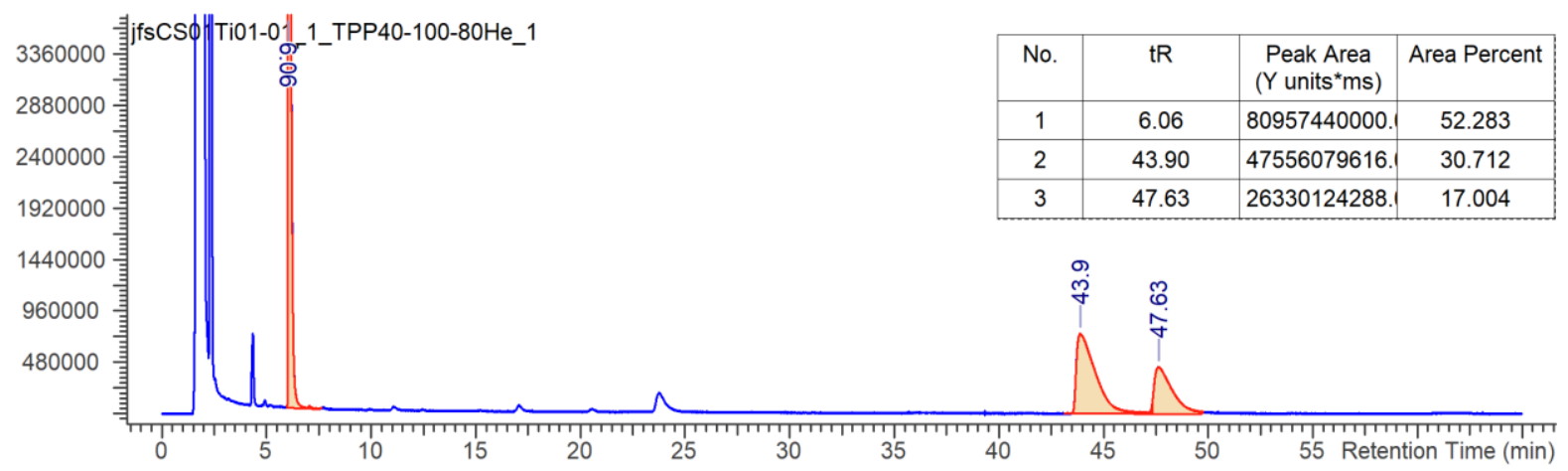

Figure S20: Experiment using ligand 1b (Table 2, Entry 2).

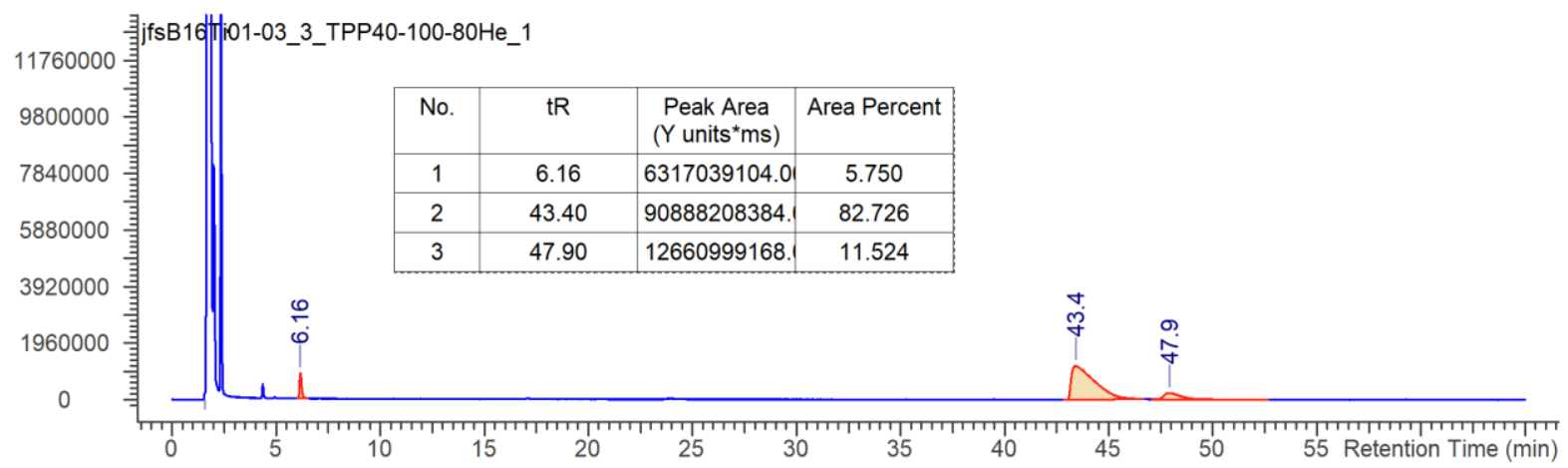

Figure S21: Experiment using ligand 1c (Table 2, Entry 3). 


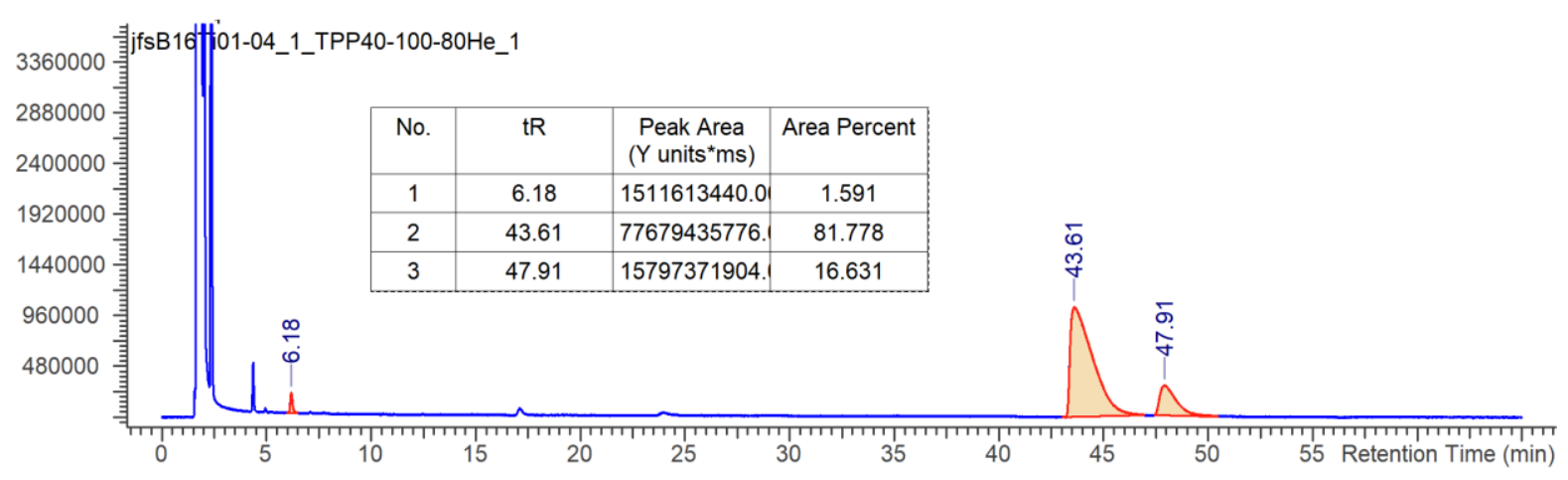

Figure S22: Experiment using ligand $1 \mathrm{c}$ at $25^{\circ} \mathrm{C}$ (Table 2, Entry 4).

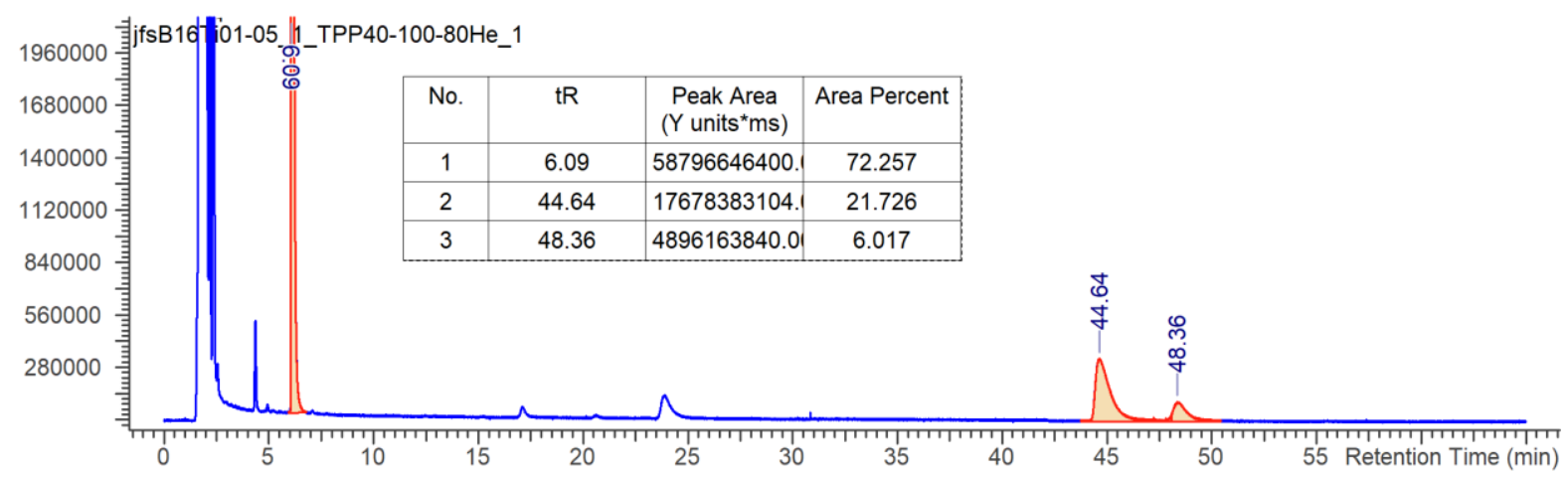

Figure S23: Experiment using ligand $1 \mathrm{c}$ at $-20^{\circ} \mathrm{C}$ (Table 2, Entry 5).

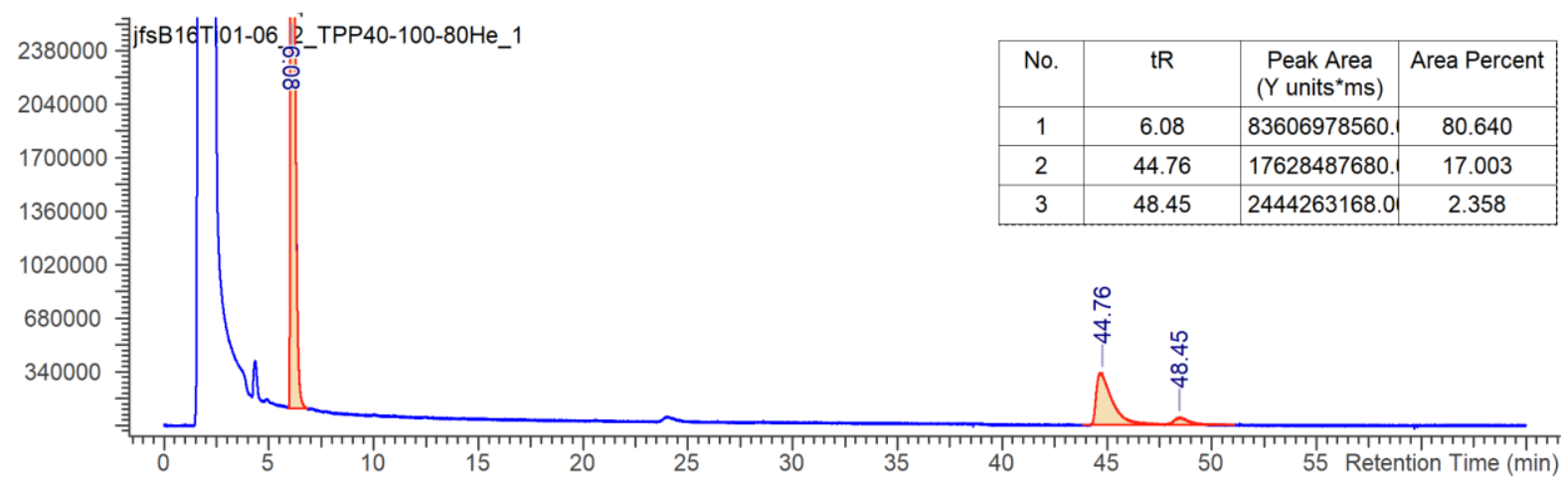

Figure S24: Experiment using ligand $\mathbf{1 c}$ and $0.02 \mathrm{M}$ substrate (Table 2, Entry 6). 


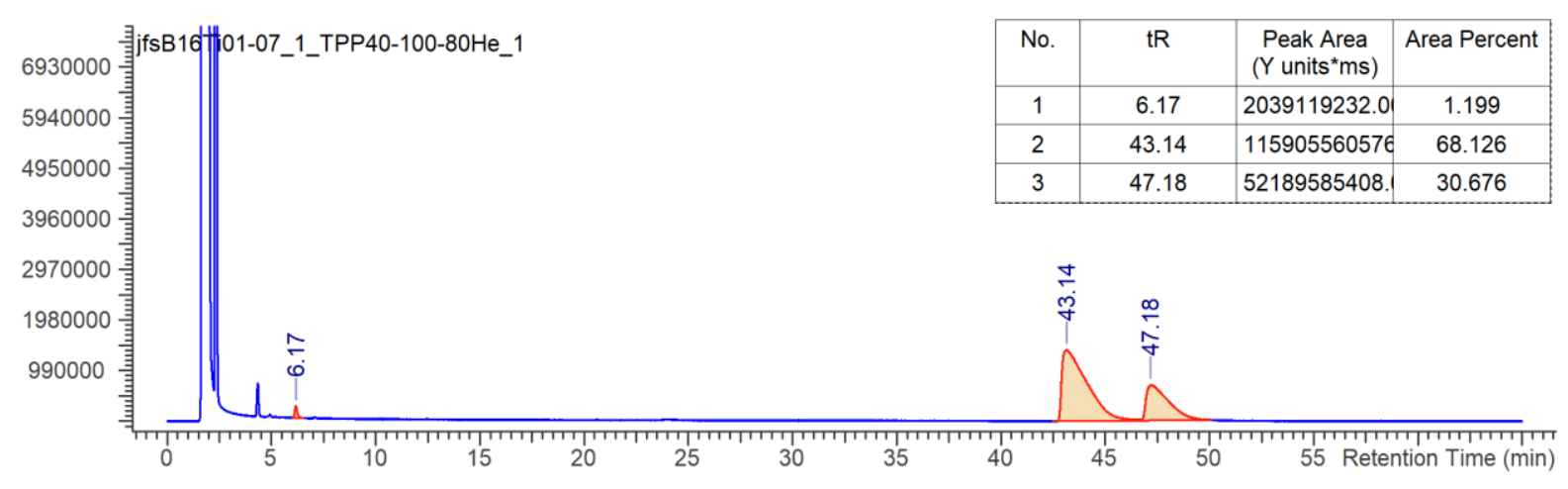

Figure S25: Experiment using ligand $1 \mathrm{c}$ and $0.375 \mathrm{M}$ substrate (Table 2, Entry 7 ).

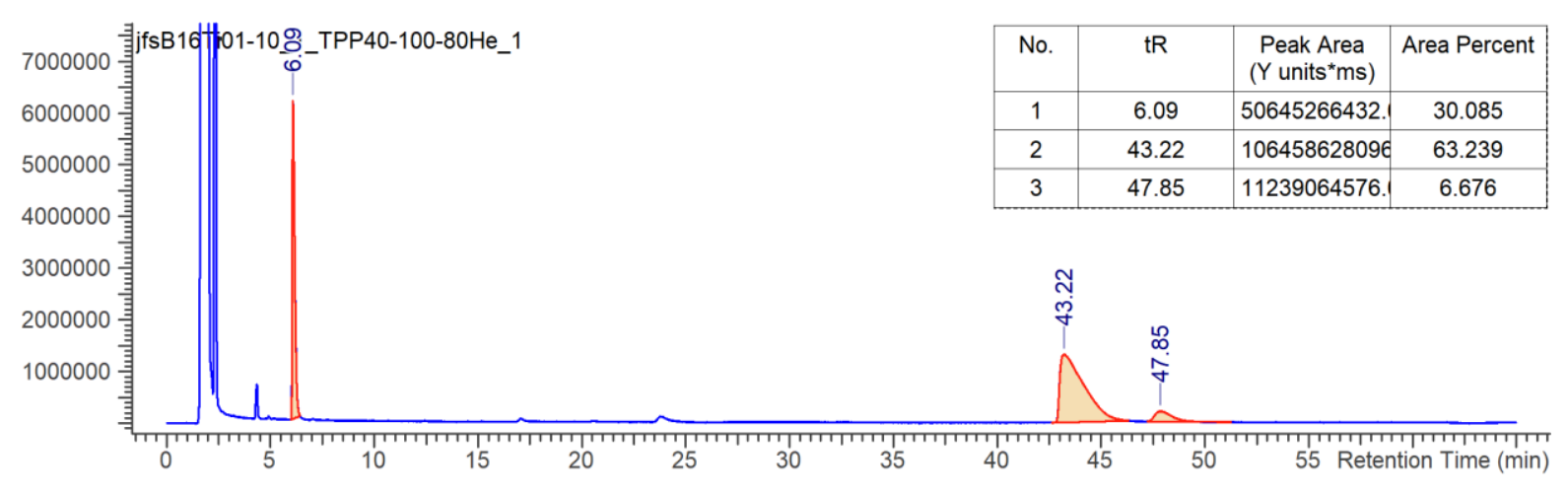

Figure S26: Experiment using ligand 1c with 40 mol\% ligand (Table 2, Entry 8).

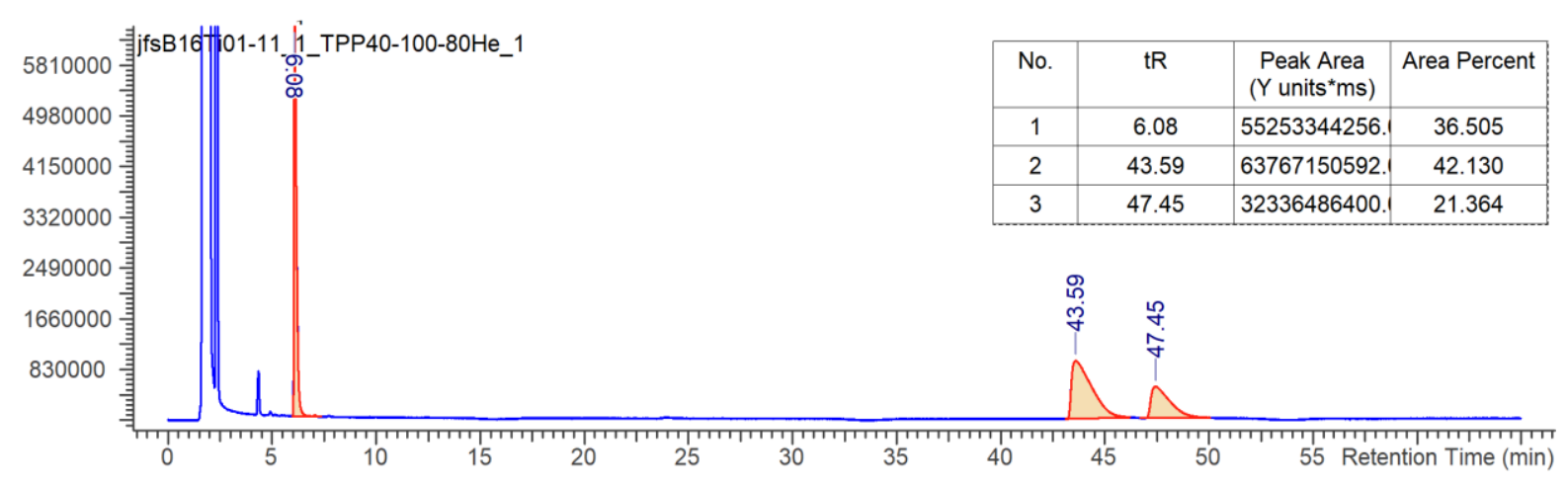

Figure S27: Experiment using ligand 1c with 0.05 mol\% ligand (Table 2, Entry 9). 


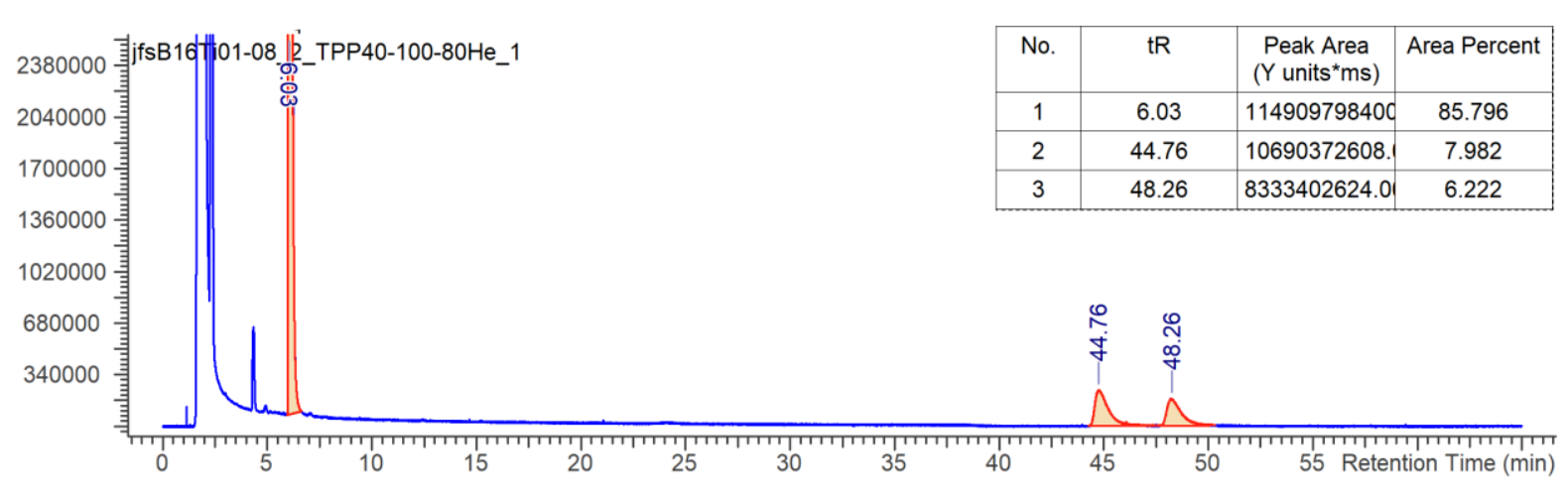

Figure S28: Experiment using ligand 1c in THF (Table 2, Entry 10).

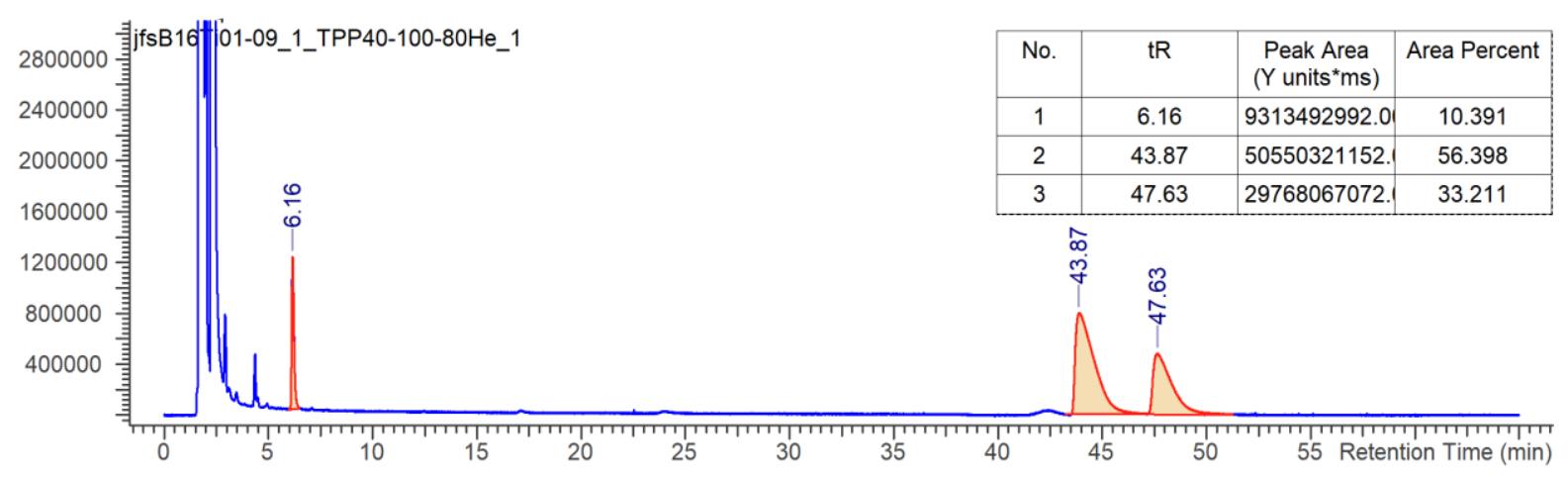

Figure S29: Experiment using ligand $\mathbf{1 c}$ in toluene (Table 2, Entry 11).

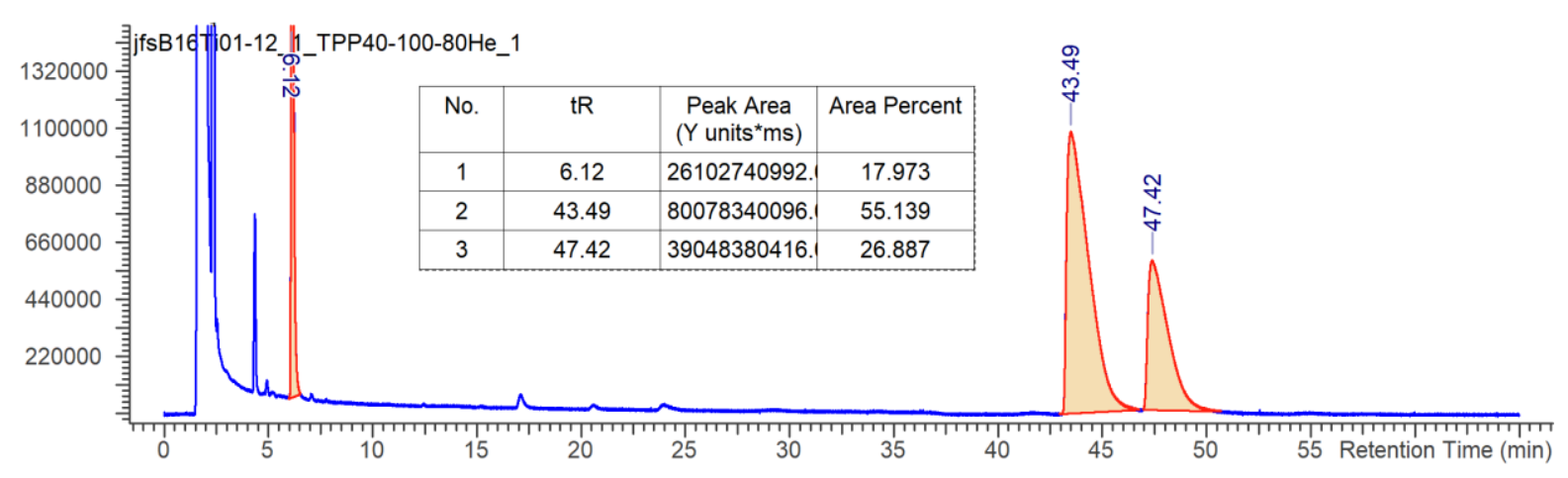

Figure S30: Experiment using ligand 1c in diethyl ether (Table 2, Entry 12). 


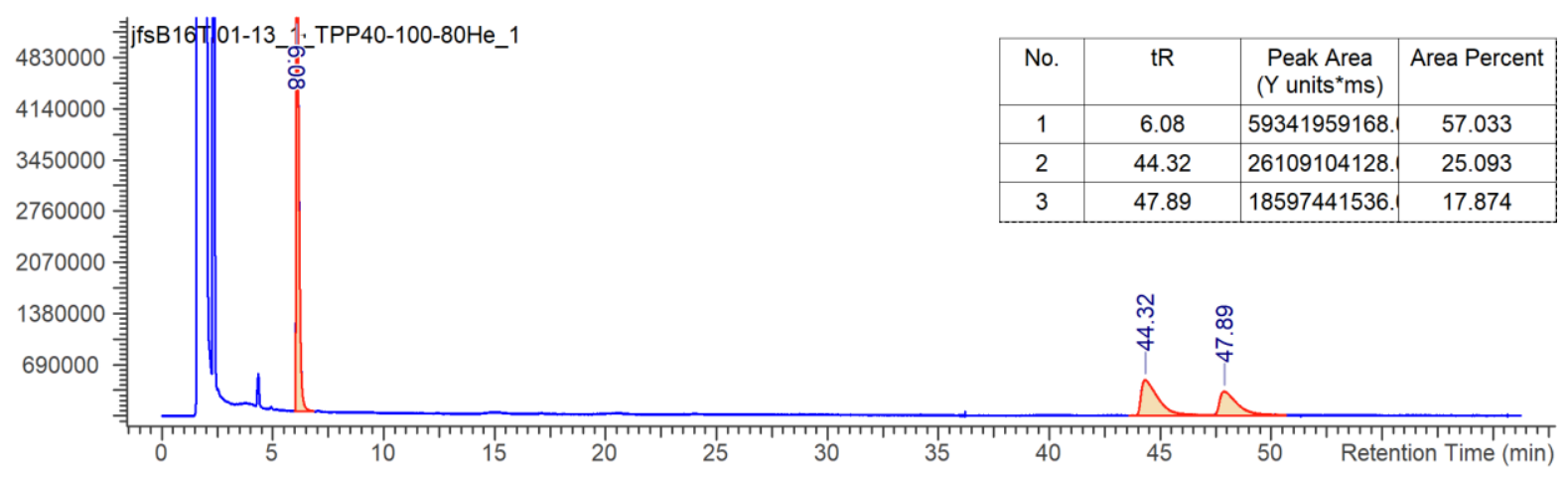

Figure S31: Experiment using ligand 1c in acetonitrile (Table 2, Entry 13).

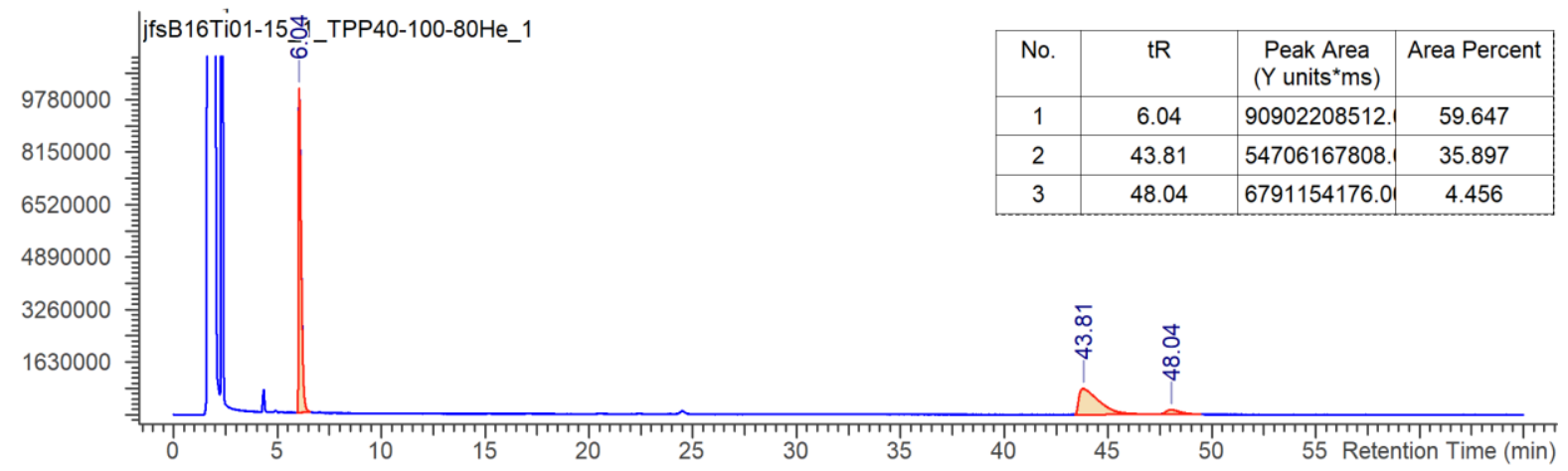

Figure S32: Experiment using ligand $\mathbf{1 c}$ in ethyl acetate (Table 2, Entry 14).

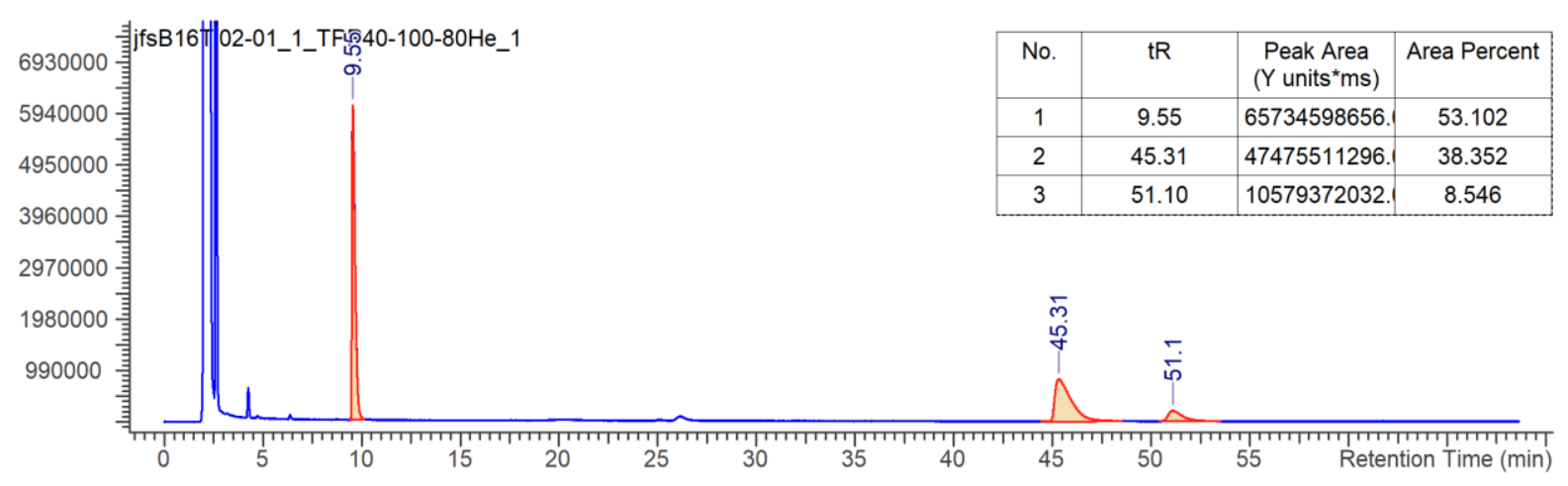

Figure S33: Experiment using ligand $\mathbf{1 c}$ and $p$-methyl benzaldehyde (Table 3, Entry 2). 


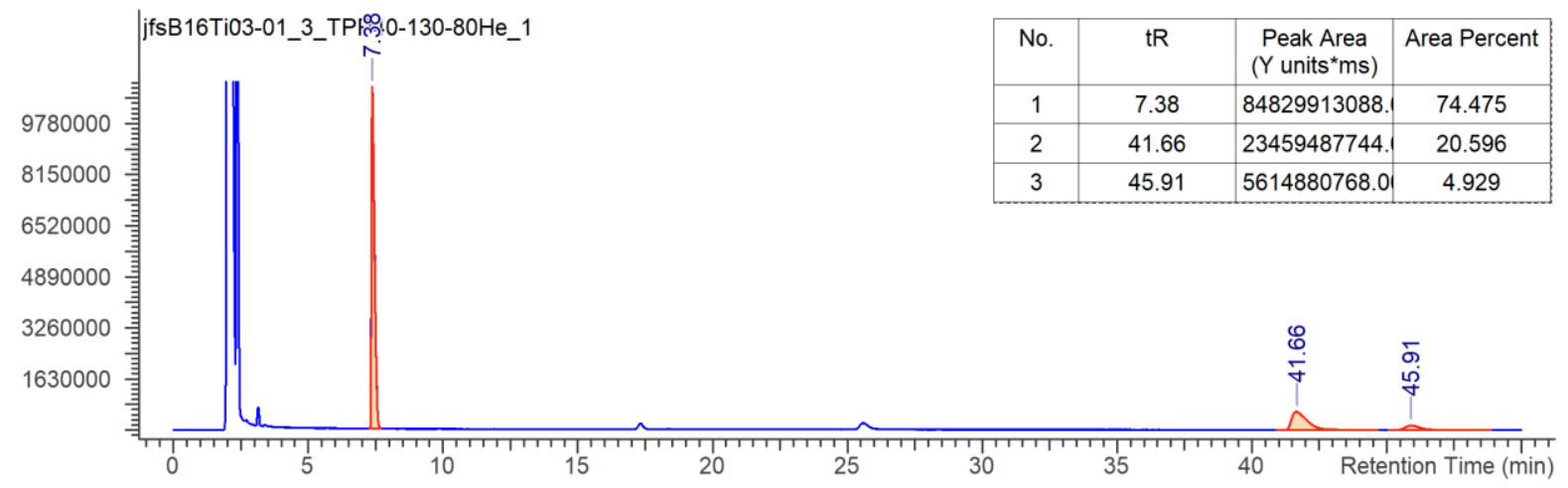

Figure S34: Experiment using ligand $\mathbf{1 c}$ and p-chlorobenzaldehyde (Table 3, Entry 3).

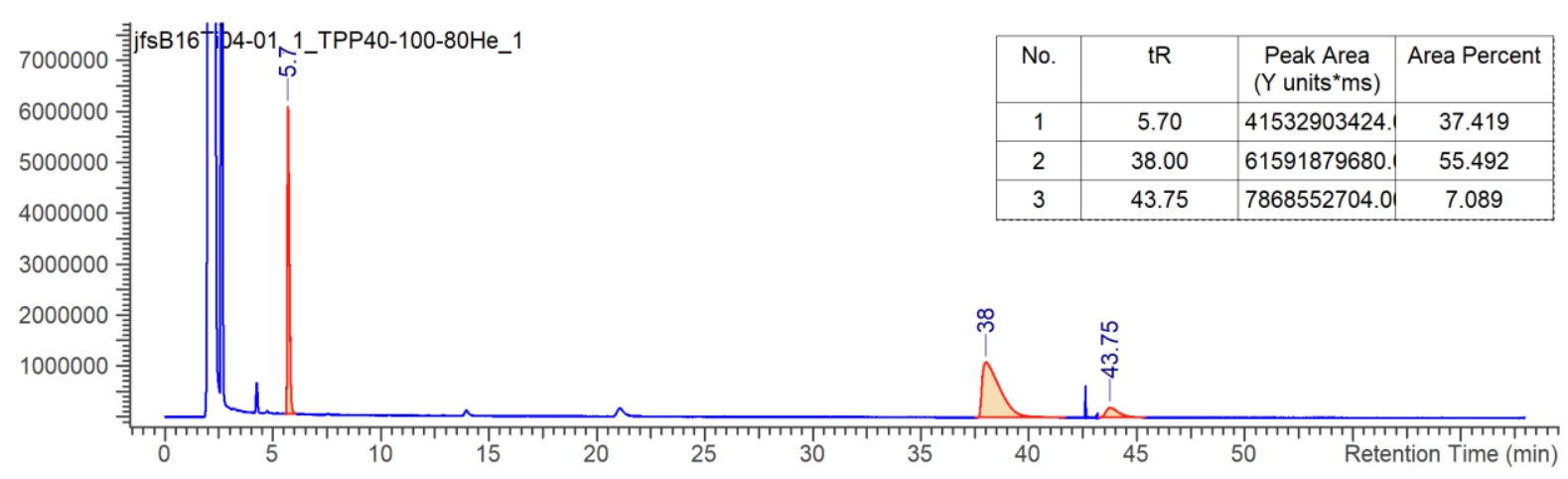

Figure S35: Experiment using ligand $\mathbf{1 c}$ and $p$-fluorobenzaldehyde (Table 3, Entry 4).

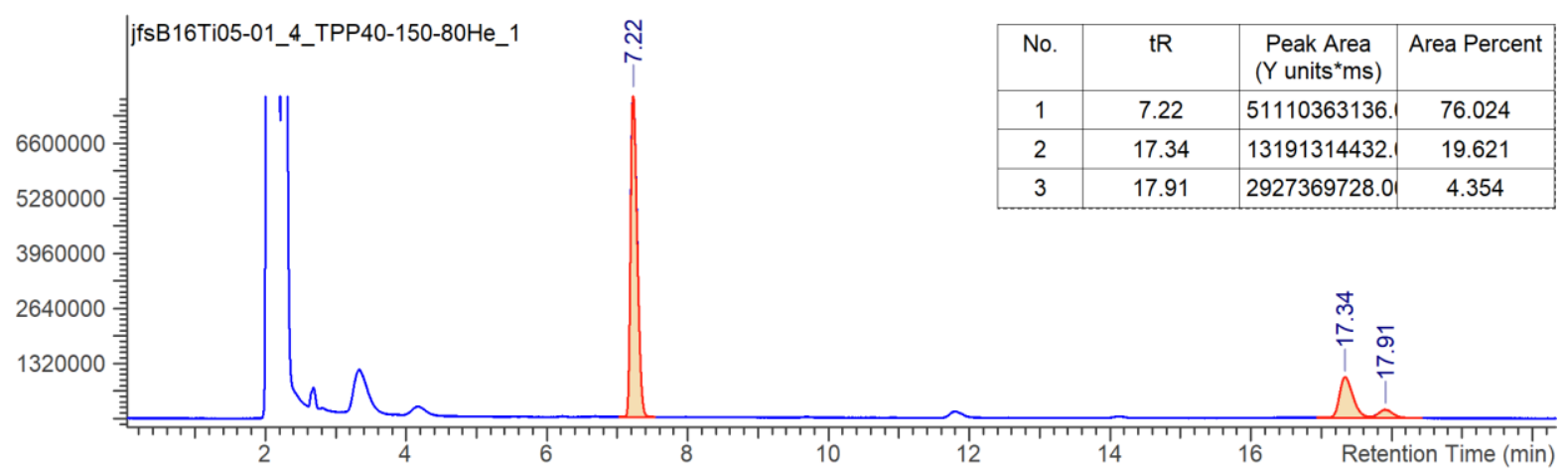

Figure S36: Experiment using ligand $\mathbf{1 c}$ and $p$-methoxy benzaldehyde (Table 3, Entry 5). 


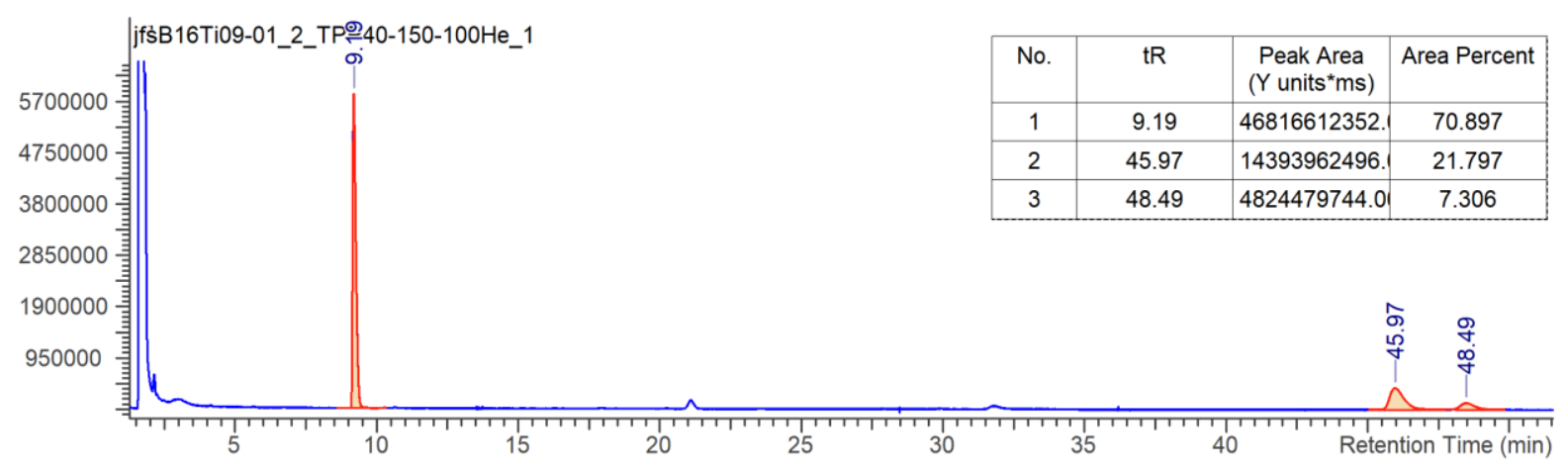

Figure S37: Experiment using ligand 1c and $p$-acetyl benzaldehyde (Table 3, Entry 6).

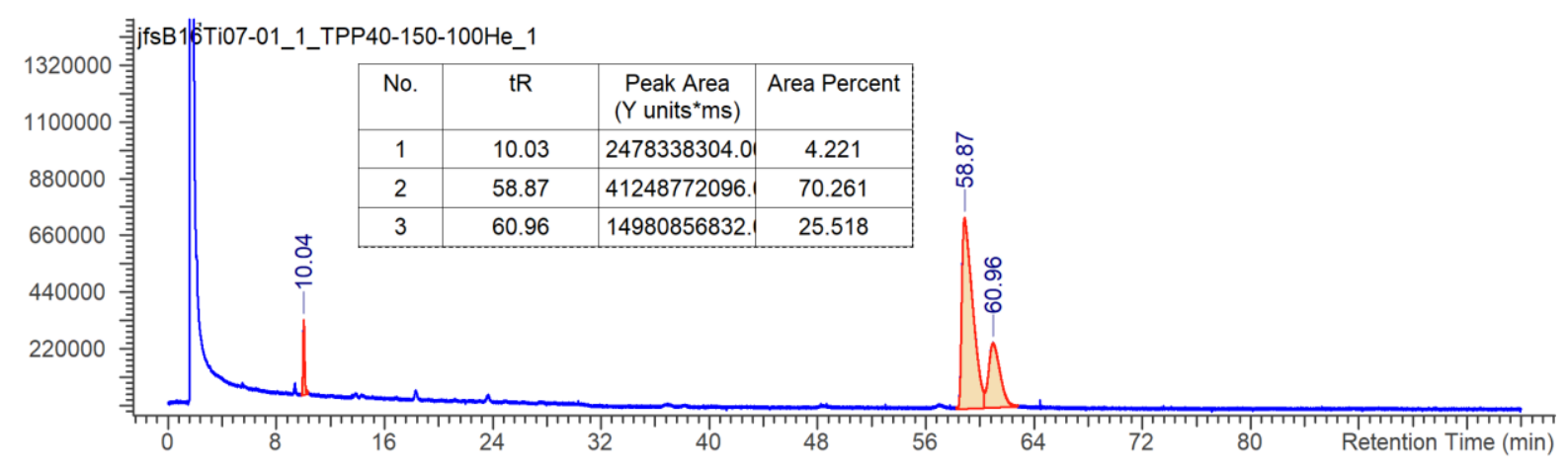

Figure S38: Experiment using ligand $\mathbf{1 c}$ and $m$-nitro benzaldehyde (Table 3, Entry 7).

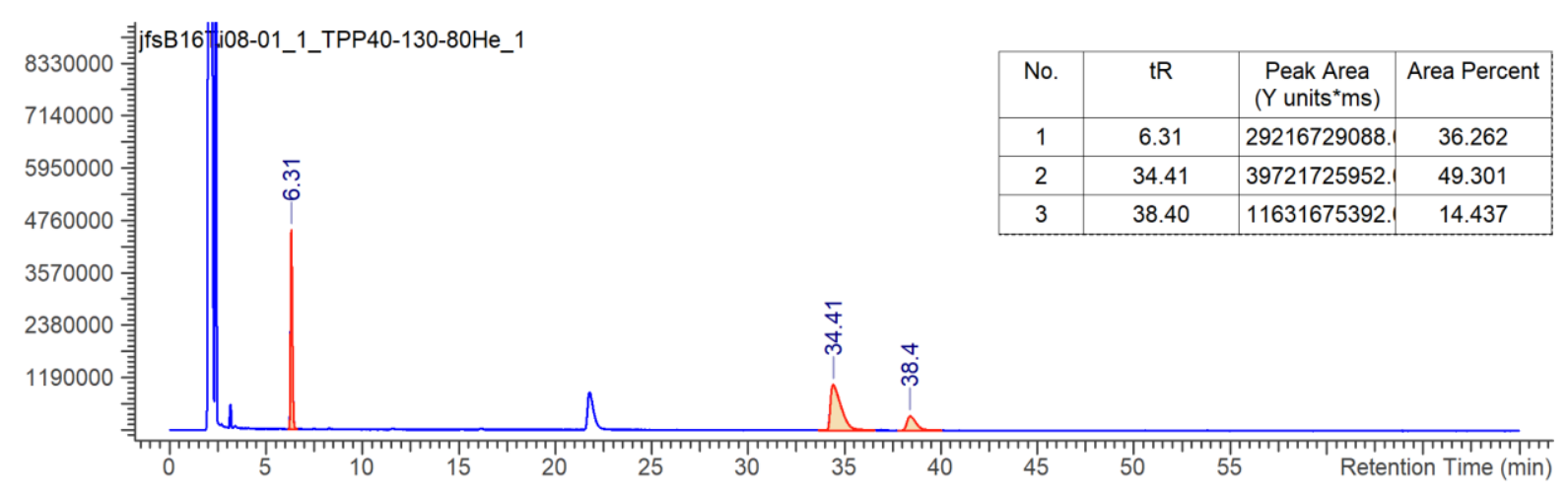

Figure S39: Experiment using ligand $\mathbf{1 c}$ and o-chlorobenzaldehyde (Table 3, Entry 8). 


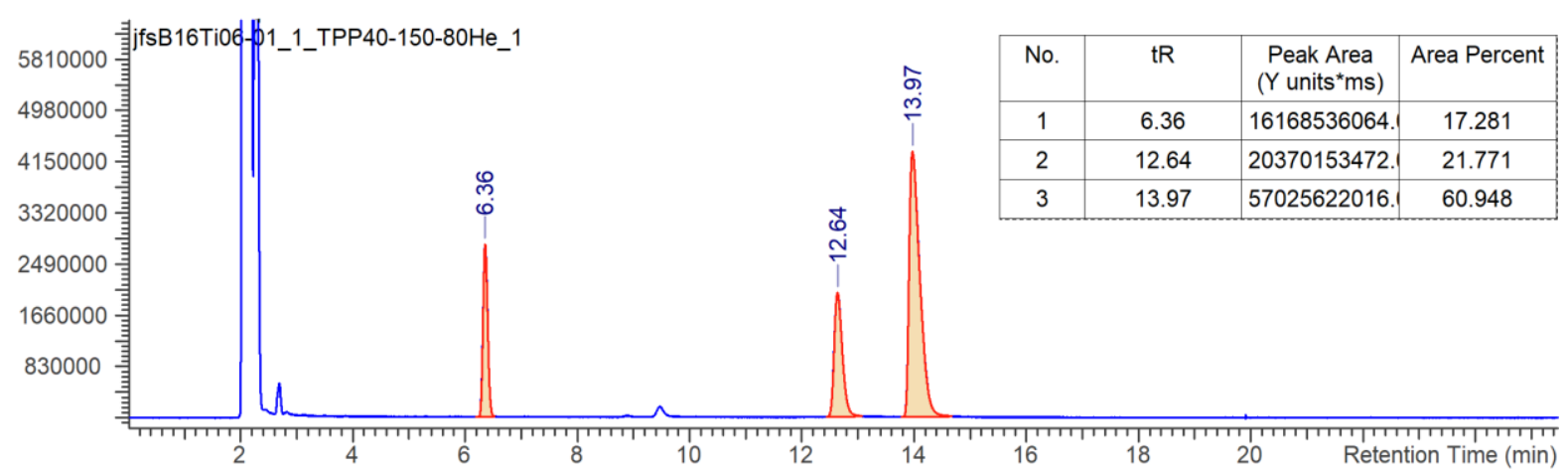

Figure S40: Experiment using ligand $\mathbf{1 c}$ and p-methoxy benzaldehyde (Table 3, Entry 9).

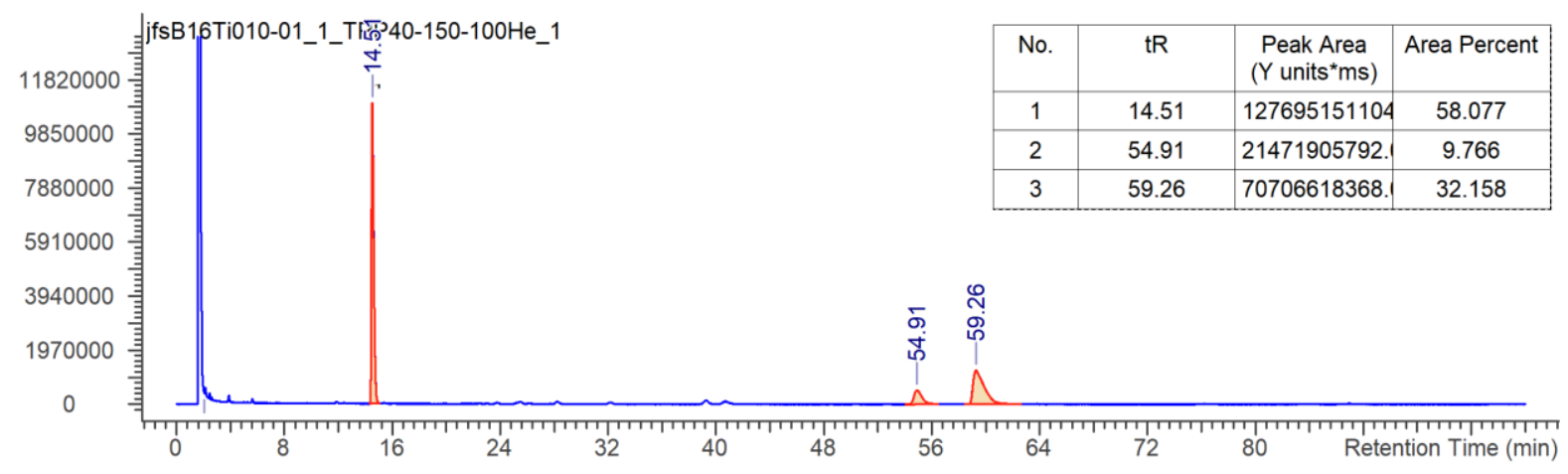

Figure S41: Experiment using ligand $\mathbf{1 c}$ and $\alpha$-naphthaldehyde (Table 3, Entry 10).

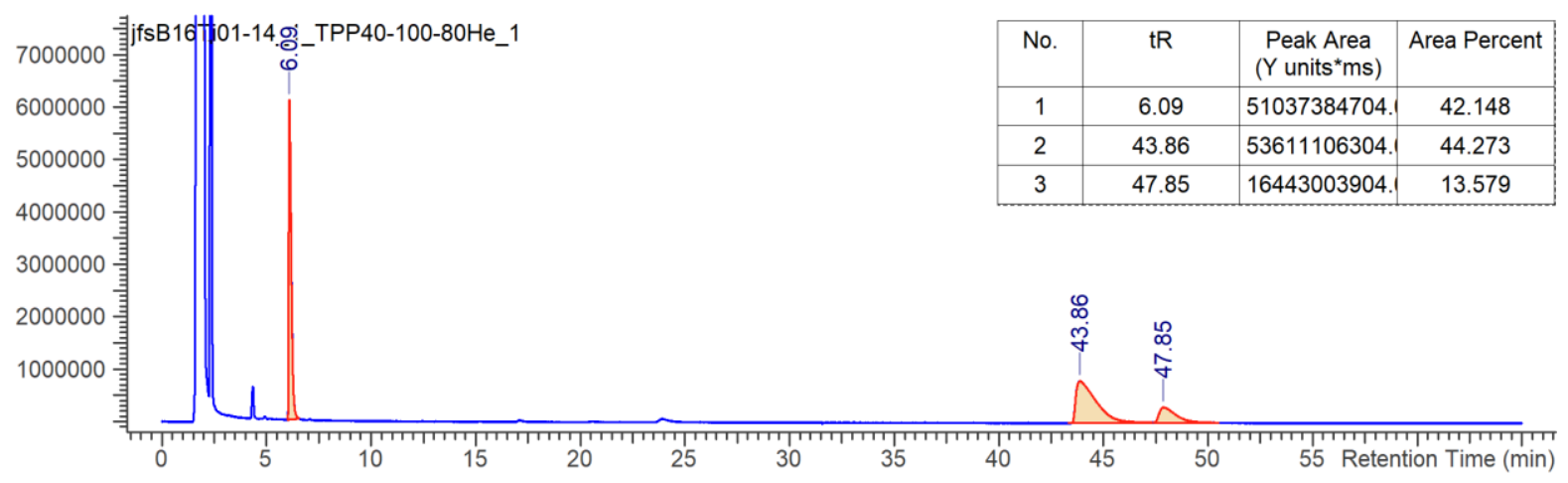

Figure S42: Experiment using ligand $\mathbf{1 c}$ and solute $\mathbf{3}$ (Table 4, Entry 1). 


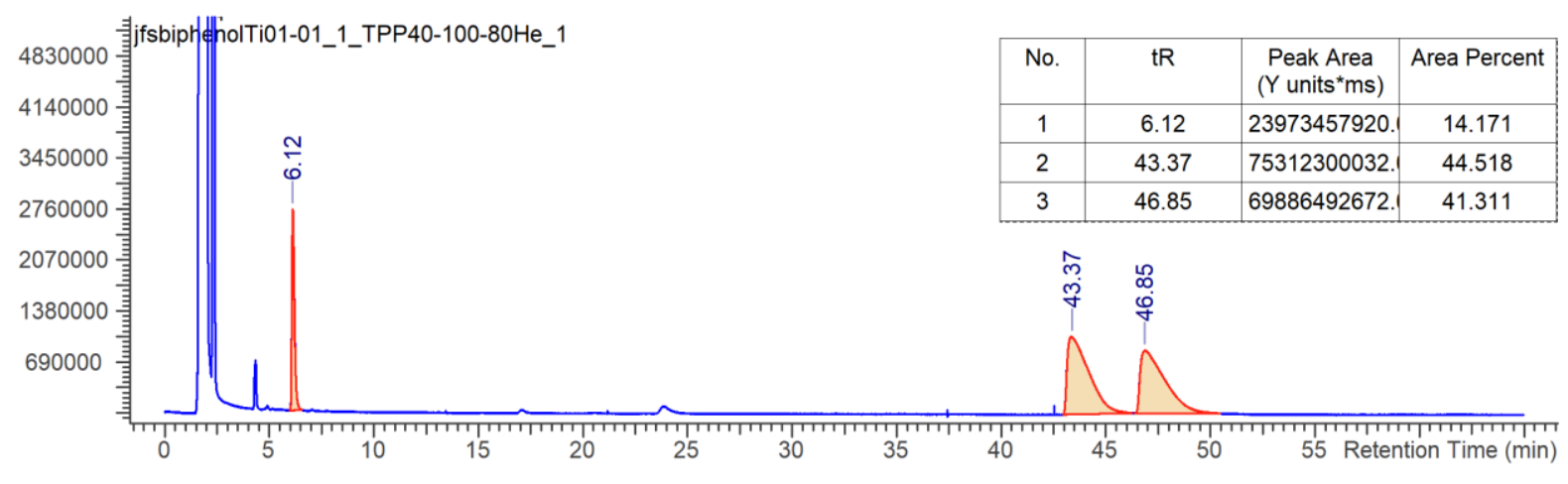

Figure S43: Experiment using ligand $\mathbf{4}$ and solute $\mathbf{3}$ (Table 4, Entry 2).

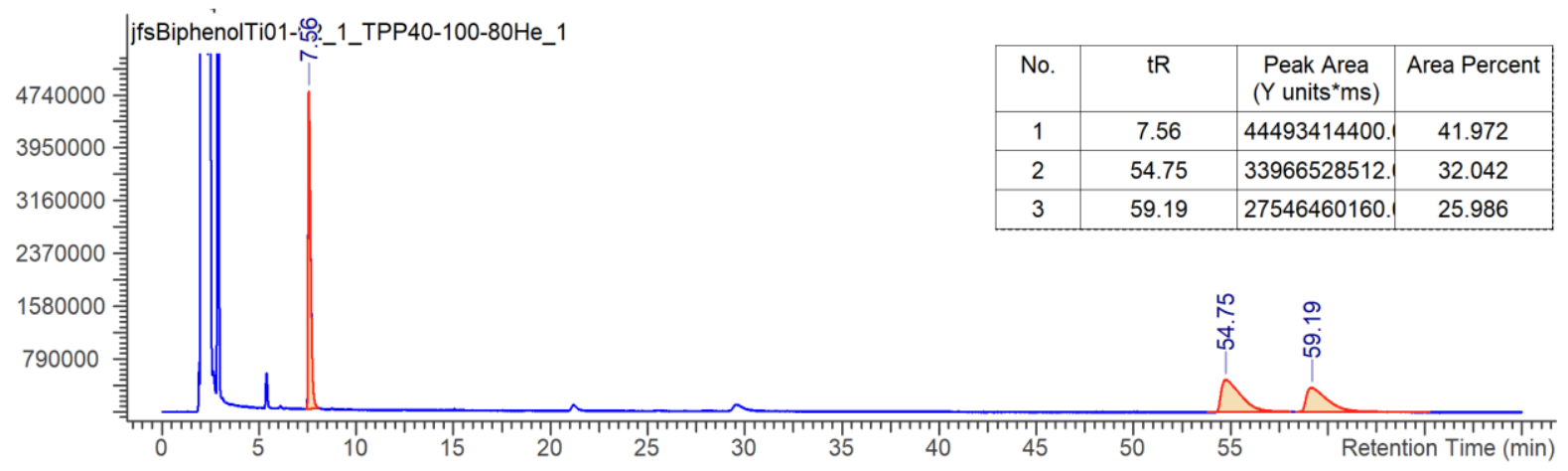

Figure S44: Experiment using ligand $\mathbf{4}$ and solute $\mathbf{3}$ with longer incubation time (Table 4, Entry 3).

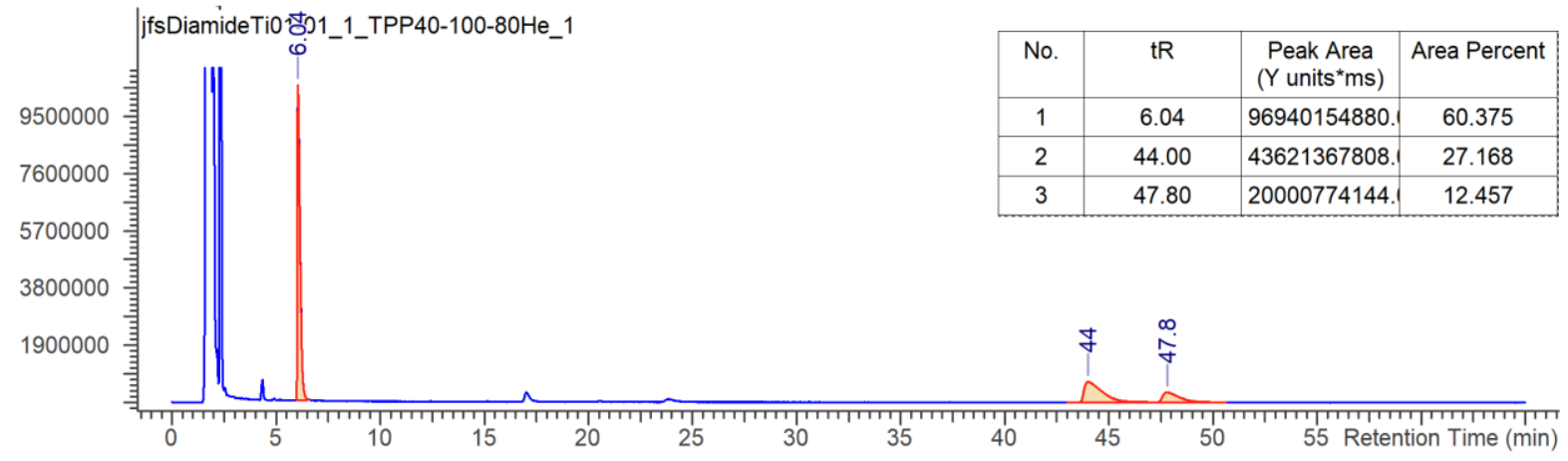

Figure S45: Experiment using solute 3 with no ligand (Table 4, Entry 4). 


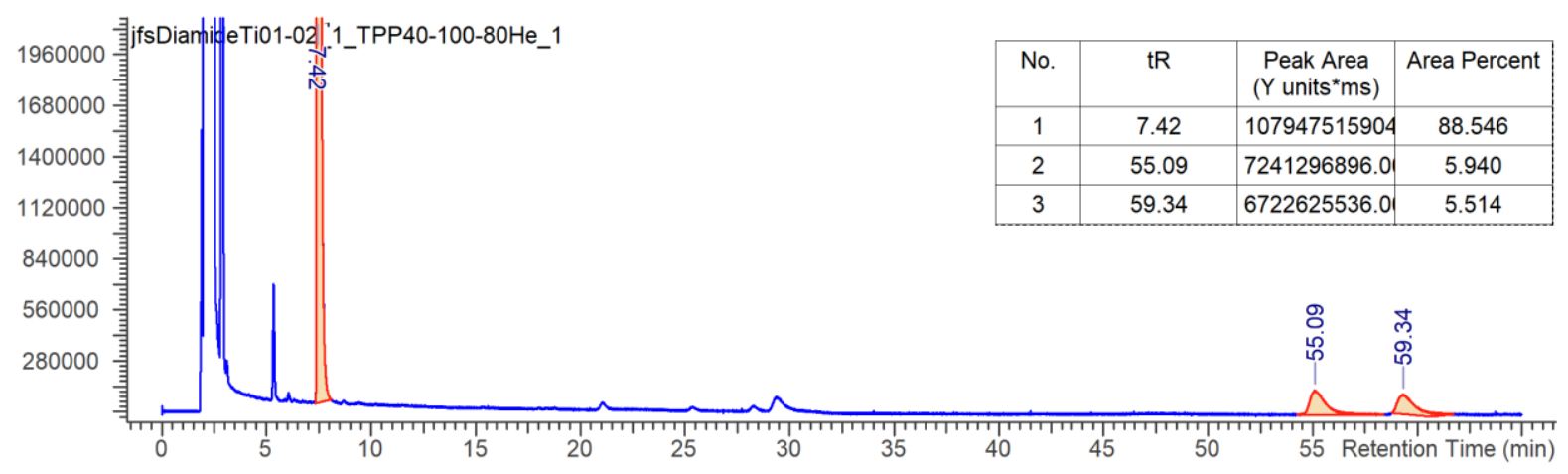

Figure S46: Experiment using solute 3 with no ligand and no titanium precursor (Table 4, Entry 5).

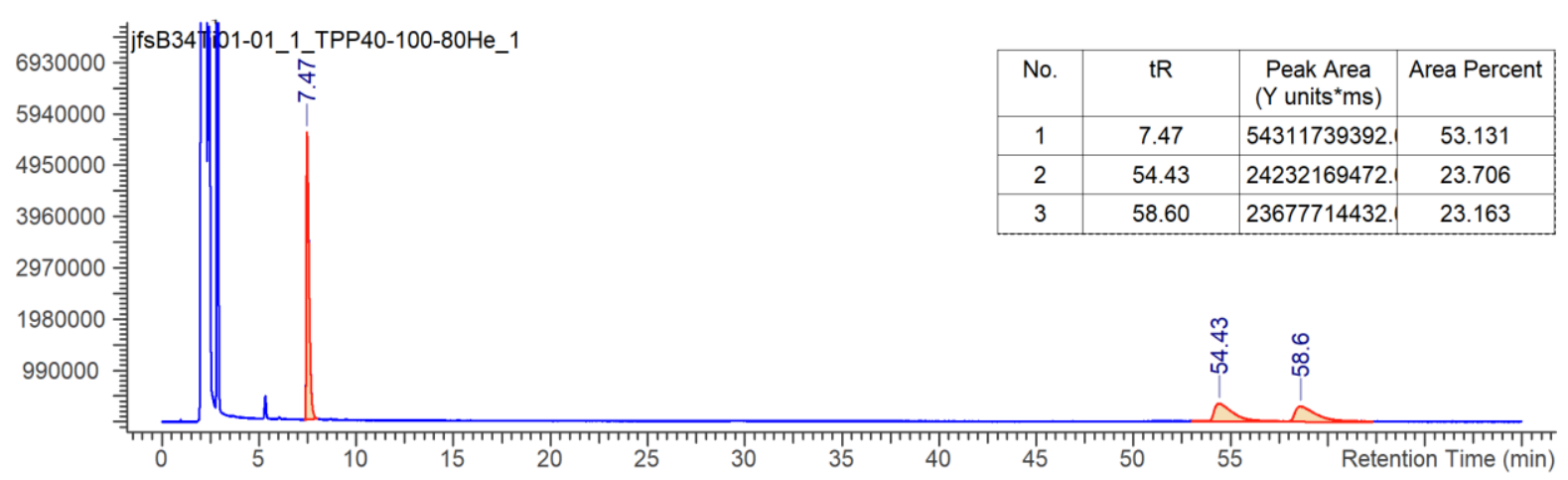

Figure S47: Experiment using ligand Me-1c with no solute (Table 4, Entry 6). 


\section{Bibliography}

1. Scholtes, J. F.; Trapp, O., Inducing Enantioselectivity in a Dynamic Catalyst by Supramolecular Interlocking Angew. Chem. Int. Ed. 2019, 58, doi:10.1002/anie.201901175.

2. Applewhite, T. H.; Niemann, C., The Interaction of $\alpha$-Chymotrypsin with a Series of $\alpha-\mathrm{N}$ Acetyl- $\alpha$-amino Acid Methylamides1. J. Am. Chem. Soc. 1959, 81, 2208-2213. 